Deep Sea Research Part II: Topical Studies in Oceanography

November 2016, Volume 133, Pages 21-38

http://dx.doi.org/10.1016/i.dsr2.2016.04.002

http://archimer.ifremer.fr/doc/00326/43724/

(C) 2016 Elsevier Ltd. All rights reserved.

\title{
A multi-model assessment of the impact of currents, waves and wind in modelling surface drifters and oil spill
}

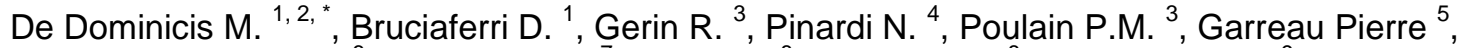 \\ Zodiatis G. ${ }^{6}$, Perivoliotis L. ${ }^{7}$, Fazioli L. ${ }^{8}$, Sorgente R. ${ }^{8}$, Manganiello C. ${ }^{9}$
}

${ }^{1}$ Istituto Nazionale di Geofisica e Vulcanologia, Bologna, Italy

${ }^{2}$ National Oceanography Centre, Liverpool, United Kingdom

${ }^{3}$ Istituto Nazionale di Oceanografia e di Geofisica Sperimentale (OGS), Trieste, Italy

${ }^{4}$ Department of Physics and Astronomy, Alma Mater Studiorum, University of Bologna, Italy

${ }^{5}$ IFREMER, Brest, France

${ }^{6}$ Oceanography Centre, University of Cyprus (OC-UCY), Nicosia, Cyprus

${ }^{7}$ Hellenic Center for Marine Research (HCMR), Athens, Greece

${ }^{8}$ CNR- IAMC, Oristano, Italy

${ }^{9}$ Italian Coast Guard Headquarters, Ministry of Infrastructures and Transports, Rome, Italy

*Corresponding author : M. De Dominicis, email address : micdom@noc.ac.uk

\begin{abstract}
:
Validation of oil spill forecasting systems suffers from a lack of data due to the scarcity of oil slick in-situ and satellite observations. Drifters (surface drifting buoys) are often considered as proxy for oil spill to overcome this problem. However, they can have different designs and consequently behave in a different way at sea, making it not straightforward to use them for oil spill model validation purposes and to account for surface currents, waves and wind when modelling them. Stemming from the need to validate the MEDESS4MS (Mediterranean Decision Support System for Marine Safety) multi-model oil spill prediction system, which allows access to several ocean, wave and meteorological operational model forecasts, an exercise at sea was carried out to collect a consistent dataset of oil slick satellite observations, in-situ data and trajectories of different type of drifters. The exercise, called MEDESS4MS Serious Game 1 (SG1), took place in the Elba Island region (Western Mediterranean Sea) during May 2014. Satellite images covering the MEDESS4MS SG1 exercise area were acquired every day and, in the case an oil spill was observed from satellite, vessels of the Italian Coast Guard (ITCG) were sent insitu to confirm the presence of the pollution. During the exercise one oil slick was found in-situ and drifters, with different water-following characteristics, were effectively deployed into the oil slick and then monitored in the following days. Although it was not possible to compare the oil slick and drifter trajectories due to a lack of satellite observations of the same oil slick in the following days, the oil slick observations in-situ and drifters trajectories were used to evaluate the quality of MEDESS4MS multimodel currents, waves and winds by using the MEDSLIK-II oil spill model. The response of the drifters to surface ocean currents, different Stokes drift parameterizations and wind drag has been examined. We found that the surface ocean currents mainly drive the transport of completely submerged drifters. The accuracy of the simulations increases with higher resolution currents and with addition of the Stokes drift, which is better estimated when provided by wave models. The wind drag improves the
\end{abstract}


modelling of drifter trajectories only in the case of partially emerged drifters, otherwise it leads to an incorrect reproduction of the drifters' direction, which is particularly evident in high speed wind conditions.

Keywords : Oil spill modelling, Drifters, Oil slick, Mediterranean, Met-ocean models 


\section{Introduction}

Verification of oil spill forecasting capabilities is both a crucial issue and a difficult task to perform. The main reason for this is the lack of time series of oil slick observations, due to the long revisit time for satellites and the scarcity of in-situ data collected. The main datasets of remote sensing oil slick observations for oil spill validation were collected during the recent major accidental oil spills (Prestige Spain, 2002; Lebanon accident, 2006; Deepwater Horizon, Gulf of Mexico 2011) and were used for the evaluation of oil spill models forecasting accuracy (Carracedo et al., 2006; Coppini et al., 2011; Mariano et al., 2011; Liu et al., 2011). Ad-hoc oceanographic surveys can be also organized to collect in-situ observations of slicks for oil spill forecasting validation (Pisano, 2016) by combining real-time satellite observations with visual and instrumental inspection of the slicks. However, when real oil slick data are lacking, drifters might help for oil spill model validation. Drifters are oceanographic instruments used to study the surface circulation and oceanographic dynamics, they are designed to be transported by ocean currents and these peculiarities make them useful tools for the validation of models of Lagrangian particle dispersion (Reed et al. 1994; Al-Rabeh et al. 2000; Price et al. 2006; Caballero et al. 2008; Brostrom et al. 2008; Sotillo et al. 2008; Abascal et al. 2009; Zodiatis et al. 2010; Cucco et al. 2012; Sayol et al. 2014). Nowadays, several different kinds of drifters exist with different shape, size and immersion depth. When using drifters for oil spill model validation it is necessary to know which are the processes that affects the dynamics of different type of drifters. Indeed, each type of drifter behaves in a different way at sea and this should be carefully considered when using them as a proxy for oil spill. Furthermore, no study so far has been done to evaluate which type of drifter really follows an oil slick. The latter is extremely complicated at sea, because it requires the deployment of different type of drifters into a real oil slick, the observation of the oil slick evolution by subsequent satellite images or by aerial survey, together with the acquisition of the drifters' trajectories. Moreover, oil slick behavior may depend on oil quantity at sea that can be just a thin film at the surface or widely dispersed in the water column, making it even more complicated to find the ideal drifter representing an oil spill.

In the framework of the MEDESS4MS (Mediterranean Decision Support System for Marine Safety) project, which has been dedicated to the maritime risks prevention and strengthening of maritime safety related to oil spill pollution in the Mediterranean, a multi-model oil spill prediction service has been built using different oil spill numerical models and national ocean and meteorological forecasting systems, in order to deliver an operational multi-model oil spill prediction service for the entire Mediterranean Sea (Zodiatis et al., 2016). Stemming from the need to validate and evaluate the accuracy of the oil spill forecasts provided by the MEDESS4MS multi-model oil spill forecasting system, an exercise at sea, called MEDESS4MS Serious Game 1 (SG1), took place in the Elba Island region, Western Mediterranean (Figure 1), during May 2014 (17 - 27 May 2014). Satellite images covering the MEDESS4MS SG1 exercise area were acquired every day and, in the case an oil spill was observed from satellite, vessels of the Italian Coast Guard (ITCG) were sent in-situ to confirm the presence of the pollution. The ITCG vessels

${ }^{*}$ Corresponding author

Email address: micdom@noc.ac.uk (M. De Dominicis) 
'ready to go' were located at the harbourmaster in Portoferraio and were equipped with drifters, with different water-following characteristics, to be deployed into the oil slicks.

During the 10 days exercise two oil slick alerts were received from the satellite systems monitoring the area (on 17 May 2014 and on 21 May 2014). One oil slick was found in-situ and drifters were effectively deployed into the oil and then monitored during the following days. Unfortunately, we did not succeed in the collection of a time series of observations of the same oil slick by satellite over the same time, which would have been helpful for the comparison between oil slick and drifter behavior. Using the drifter data collected, the main objectives of this paper are: (i) evaluation of the quality of MEDESS4MS multi-model currents, waves and winds; (ii) comprehension of the differences between different drifter behavior at sea and assessment of the capabilities to simulate them.

The paper is organized as follows: Section 2 describes the data collected for oil spill forecasting validation (remote sensing data, in-situ data and drifters); Section 3 presents the modelling methodology used and the description of the experiments performed; Section 4 reports the validation results, and Section 5 summarizes our conclusions.

\section{Data}

\subsection{Data from satellite}

The MEDESS4MS SG1 aimed to detect oil slicks by satellite using SAR images covering the exercise area available through CleanSeaNet2 (CSN-2) and COSMOSKYMED (CSK) services for the entire exercise period. The acquisition of two satellite images every day from CSN-2 or from CSK were planned. The CSK system allows a more frequent revisit time of the same area (12 hours, depending on the size of the area). However, the planned images were not available every day.

During the exercise period, two oil slick alerts were received from the satellite monitoring systems. The first one was on the morning of the 17th May 2014 at 05:38 UTC, when an oil spill was observed by CleanSeaNet2 (CSN-2). Figure 2-a shows the original satellite image, while Figure 2-b is the output of the CSN-2 automatic detection algorithm (dark area in the northern part of the domain of Figure 2-a represents a low wind area or ocean features, not an oil slick). The oil spill was reported as being composed of 7 oil slick patches, the centre positions of those are reported in Table 1. The ITCG vessel was sent to confirm the oil spill in-situ, which was found at 07:08 UTC by visual detection (i.e. iridescence). The oil was sampled in 4 different positions reported in Table 2.

The second slick alert was received on the morning of the 21st of May 2014 at 05:07 UTC, when two oil slicks were detected by the CSK satellite system, west of Elba Island (see Figure 1). The ITCG vessel went immediately to search in-situ. However, by visual inspection of the area, it was not possible to identify any oil slick. In addition, an ITCG plane ATR 42 equipped with a side-looking airbone radar (SLAR) surveyed the area, and it confirmed that it was not possible to detect any oil slick. 


\begin{tabular}{llll}
\hline \hline Slick ref. & Latitude $^{\prime}$ & Longitude & Area $\left(\mathrm{km}^{2}\right)$ \\
\hline $\mathrm{A}$ & $42^{\circ} 57.93^{\prime} \mathrm{N}$ & $10^{\circ} 00.42^{\prime} \mathrm{E}$ & 0.97 \\
$\mathrm{~B}$ & $42^{\circ} 57.40^{\prime} \mathrm{N}$ & $09^{\circ} 58.98^{\prime} \mathrm{E}$ & 0.03 \\
$\mathrm{C}$ & $42^{\circ} 57.63^{\prime} \mathrm{N}$ & $09^{\circ} 59.53^{\prime} \mathrm{E}$ & 0.16 \\
$\mathrm{D}$ & $42^{\circ} 57.36^{\prime} \mathrm{N}$ & $10^{\circ} 01.00^{\prime} \mathrm{E}$ & 0.24 \\
$\mathrm{E}$ & $42^{\circ} 58.70^{\prime} \mathrm{N}$ & $10^{\circ} 01.27^{\prime} \mathrm{E}$ & 0.09 \\
$\mathrm{~F}$ & $42^{\circ} 57.17^{\prime} \mathrm{N}$ & $09^{\circ} 58.68^{\prime} \mathrm{E}$ & 0.16 \\
$\mathrm{G}$ & $42^{\circ} 58.55^{\prime} \mathrm{N}$ & $10^{\circ} 00.93^{\prime} \mathrm{E}$ & 0.13 \\
\hline \hline
\end{tabular}

Table 1: List of slicks composing the spill observed on the 17 May 2014 at 05:38 UTC by the CSN-2 system.

\begin{tabular}{llll}
\hline \hline SAMPLE ID & Time (UTC) & Latitude & Longitude \\
\hline M1 & $7: 08$ & $42^{\circ} 58.01^{\prime} \mathrm{N}$ & $9^{\circ} 59.26^{\prime} \mathrm{E}$ \\
M2 & $7: 35$ & $42^{\circ} 58.82^{\prime} \mathrm{N}$ & $9^{\circ} 59.34^{\prime} \mathrm{E}$ \\
M3 & $8: 27$ & $42^{\circ} 57.90^{\prime} \mathrm{N}$ & $9^{\circ} 58.33^{\prime} \mathrm{E}$ \\
M4 & $8: 49$ & $42^{\circ} 58.21^{\prime} \mathrm{N}$ & $9^{\circ} 59.37^{\prime} \mathrm{E}$ \\
\hline \hline
\end{tabular}

Table 2: Oil Sampling positions and time on the 17 May 2014.

\subsection{Drifters}

Drifters were released into the observed oil slick on the 17th May 2014. In particular, in order to be able to distinguish between the uppermost meter of the water column and the purely superficial flow, some drifters with different water-following characteristics (CODE, iSLDMB, iSPHERE, MAR-GE/T) were released inside the oil slick.

CODE surface drifters (Davis, 1985) are made of a $1 \mathrm{~m}$ long vertical tube with four wings extending radially from the tube over its entire length. When in water they are completely submerged, except for a small antenna on the top of the tube and four small floats attached on the upper extremities of the wings. The design of iSLDMB (Iridium Self-locating Marker Buoy) drifters is based on the CODE/Davis style oceanographic surface drifters, but they are made of a $60 \mathrm{~cm}$ vertical tube. The CODE drifter is designed to minimize the effect of the wind on the emerged part of the instrument (Poulain, 1999). iSPHERE (Iridium SPHERE) surface drifters are $39.5 \mathrm{~cm}$ diameter spheres (Price et al., 2006), where in water the iSPHERE drifter is half submerged. MAR-GE/T drifters have a cylindrical shape, with a diameter of $13.4 \mathrm{~cm}$ and height of $28 \mathrm{~cm}$, when in water the drifter is submerged for $1 / 3$ of its height.

The deployment of the different types of drifters was aimed at revealing the proportions in which the drifters follow the wind, currents and waves. The deployment time and positions are listed in Table 3. The 2 iSPHERE drifters and the 2 CODE drifters were recovered after 1 day at sea, while the iSLDMB and MAR-GE/T were recovered after 7 days at sea. From Fig. 3-a it is possible to observe that CODE and iSLDMB followed a similar trajectory, while they moved in a different direction and slower than the iSPHERE and MAR-GE/T drifters. It is worth noting that 2 CODE drifters were moving together, the same can be observed for the 2 iSPHERE drifters. This allow us to be more confident in saying that the different behavior is due to the different drifter shapes, rather than to sub-mesoscale ocean processes. From Fig. 3-b it is evident that, 
after a few hours at sea, iSLDMB and MAR-GE/T diverged and described a completely different trajectory.

\begin{tabular}{llll}
\hline \hline Drifter Type & Time (UTC) & Latitude & Longitude \\
\hline iSPHERE & $11: 38$ & $42^{\circ} 58.23^{\prime} \mathrm{N}$ & $9^{\circ} 59.03^{\prime} \mathrm{E}$ \\
iSPHERE & $11: 39$ & $42^{\circ} 58.18^{\prime} \mathrm{N}$ & $9^{\circ} 59.03^{\prime} \mathrm{E}$ \\
MAR-GE/T & $11: 39$ & $42^{\circ} 58.14^{\prime} \mathrm{N}$ & $9^{\circ} 59.01^{\prime} \mathrm{E}$ \\
CODE & $12: 08$ & $42^{\circ} 58.29^{\prime} \mathrm{N}$ & $9^{\circ} 58.83^{\prime} \mathrm{E}$ \\
iSLDMB & $12: 00$ & $42^{\circ} 58.17^{\prime} \mathrm{N}$ & $9^{\circ} 58.86^{\prime} \mathrm{E}$ \\
CODE & $12: 04$ & $42^{\circ} 58.16^{\prime} \mathrm{N}$ & $9^{\circ} 58.79^{\prime} \mathrm{E}$ \\
\hline \hline
\end{tabular}

Table 3: Positions and time of drifter deployments into the oil slick on 17 May 2014.

\section{Method}

Lagrangian models are a powerful tool for modelling the marine transport of pollution or floating objects. A Lagrangian model tracks a set of tracer particles forward in time from a source. In this work, particles can represent a floating object or surface oil slick and they can be passively transported by the upper ocean currents, waves and winds. In the case of an oil slick or any other pollutant, the Lagrangian model should also reproduce the transformation processes that affect the pollutant physical and chemical characteristics. In this study our attempt is to differentiate the effects of the currents and waves on the transport of a surface oil slick or floating object and to correctly simulate the effect of the wind on different kind of drifters.

The first objective of this work is to evaluate the quality of the multi-model forcing data (currents, wave, winds) provided by the MEDESS4MS system, that can drive the oil slick or floating object motion at sea. MEDESS4MS allows access to the forecasts of temperature and sea currents from different ocean models with variable horizontal spatial resolution and with 1-hour temporal resolution, as well as access to wave conditions and winds in a variety of temporal and spatial resolution (full description of the MEDESS4MS ocean, wave and meteorological model is given in Zodiatis et al. (2016)). The MEDESS4MS multi-model oil spill prediction system allows the use of 4 different oil spill models to forecast the trajectory of the oil slick observed by the satellite system and of the drifters released in the area of the experiment. However, only one of the MEDESS4MS oil spill models, MEDSLIK-II (see Sect. 3.1), has been used in this work to simulate the drifters' trajectories and the oil slick observed from satellite. This choice has been done to reduce the degrees of freedom, as it is necessary to evaluate the quality of the different ocean, wave and wind forcings. All the MEDESS4MS models that can provide sea, wave and wind state for the SG1 region have been used. A full description of the combination of models used is given in Sect. 3.2.

The second objective of this study is to understand the magnitude of the wave-induced transport. The tracer transport is mainly generated by the upper ocean currents and when dealing with models we must take care to understand what are the upper ocean currents provided by the hydrodynamic models and which processes are represented or not by the model data. When talking about advection by upper ocean currents we must specify that this includes parts which are due to the mean drift due to surface waves (Stokes, 1847) and mean currents forced by the waves. The Stokes drift is not represented by a hydrodynamic Eulerian model, while the mean 
currents forced by the waves can be represented by an hydrodynamic model only when it is coupled with a wave model. In the present work the hydrodynamic models used (available from the MEDESS4MS system) do not include the interaction between wave momentum and current momentum. Although the interaction between the Ekman current and Stokes drift can be even more important than the Stokes drift itself (Smith, 2006; McWilliams et al., 2004; Mellor, 2003, 2008; Ardhuin et al., 2008), the exact representation of the wave effect on the mean current field is still being debated and this term it is still not included in state-of-the-art hydrodynamic models. Thus, in this work, we cannot examine the effect of wave-induced currents on tracer transport, but we explore and compare different approaches to compute the Stokes drift, focusing on the benefit of having a dedicated forecasting wave system that can provide wave statistics to be fed into the oil spill/trajectory model.

The third objective is to shed light on how to correctly use the wind velocity in the simulation of tracers or drifters transport. In the past, the drift velocity of a surface oil slick or surface drifter was considered to be the sum of a fraction of the wind velocity (wind drift or wind correction) and an estimate of the current fields from OGCM. The wind correction has been interpreted in different ways in the past thirty years. Initially, it was necessary in order to reproduce the surface Ekman currents, i.e., the local wind effects that were not properly resolved by low-resolution, climatological models. A practical 'rule of thumb' was to add to the ocean currents a wind drift assumed to be $3 \%$ of the wind velocity and with a deviation angle between $0^{\circ}$ and $25^{\circ}$ (Al-Rabeh, 1994; Reed et al., 1994). Nowadays, a correct representation of the Ekman currents is provided by OGCMs and that kind of wind correction is now obsolete. In more recent works, a $1 \%$ of the wind velocity has been added to the ocean currents in the same direction of the wind $\left(0^{\circ}\right.$ deviation angle) to roughly represent the effect of waves, as done by Coppini et al. (2011) and Liubartseva et al. (2015). Indeed, as demonstrated by De Dominicis et al. (2013a) that approach is almost equivalent to the calculation of the Stokes drift using the empirical JONSWAP wave spectrum parameterization. Thus, if the upper ocean currents are correctly reproduced by an hydrodynamic model and a wave forecasting system is available, there is no need to add a wind correction to the ocean surface currents. Although these are both a fraction of the wind velocity, the above described wind corrections must not be confused with the direct drag of the wind on a floating objects that can be modelled by assessing the leeway (Breivik et al., 2011). In this work, by using drifters with different immersion depth we want to show how the wind drag effect (leeway) has a substantial importance only in the case of partially emerged floating objects.

\subsection{MEDSLIK-II}

The oil spill model code MEDSLIK-II (De Dominicis et al., 2013b,a; Bruciaferri and MEDSLIKII system team, 2015) is designed to be used to predict the transport and weathering of an oil spill or to simulate the movement of a floating object. MEDSLIK-II is a Lagrangian model, which means that the oil slick is represented by a number $\mathrm{N}$ of constituent particles that move by advection and disperse by Lagrangian turbulent diffusion. The advection is taken to be the sum of different components:

$$
\begin{aligned}
d \mathbf{x}_{k}(t)= & {\left[\mathbf{U}_{C}\left(x_{k}, y_{k}, t\right)+\mathbf{U}_{S}\left(x_{k}, y_{k}, t\right)+\mathbf{U}_{W}\left(x_{k}, y_{k}, t\right)\right.} \\
& \left.+\mathbf{U}_{D}\left(x_{k}, y_{k}, t\right)\right] d t+d \mathbf{x}_{k}^{\prime}(t)
\end{aligned}
$$

where $\mathbf{U}_{C}$ is the wind, buoyancy and pressure driven large scale current velocity field, $\mathbf{U}_{W}$ is the wind-driven sea surface currents velocity correction term, $\mathbf{U}_{S}$ is the wave-induced current term 
(Stokes drift velocity), $\mathbf{U}_{D}$ is the wind drag velocity due to emergent part of the objects at the surface and $d \mathbf{x}_{k}^{\prime}(t)$ is the displacement due to the turbulent diffusion.

The term $\mathbf{U}_{C}$ represents the surface currents that can be provided by an oceanographic model. However, in numerical circulation models the surface velocity represents the mean velocity in the surface layer that can vary from few centimeters to few meters depending on the vertical model discretization. Thus, surface currents from an oceanographic model do not actually represent the currents at $0 \mathrm{~m}$, but are just the currents at the first level of the model.

Several approaches exist to account for the term $\mathbf{U}_{S}$; the Stokes drift can be approximated using only wind speed and direction, and it can be written as:

$$
\begin{aligned}
U_{S} & =D_{S} \cos \vartheta \\
V_{S} & =D_{S} \sin \vartheta
\end{aligned}
$$

where $\left(W_{x}, W_{y}\right)$ are the wind velocity components at $10 \mathrm{~m}, \vartheta=\operatorname{arctg}\left(\frac{W_{y}}{W_{x}}\right)$ is the wind direction and $D_{S}$ is the Stokes drift velocity intensity in the direction of the wave propagation, at the surface and for deep-water waves, is defined as:

$$
D_{S}(z=0)=2 \int_{0}^{\infty} \omega k(\omega) S(\omega) d \omega
$$

where $\omega$ is angular frequency, $k$ is wave-number, and $S(\omega)$ is wave spectrum. The wave spectrum, $S(\omega)$, can be calculated using empirical parameterizations. MEDSLIK-II allows to use Joint North Sea Wave Project (JONSWAP) spectrum parameterization (Hasselmann et al., 1973), that describes the wave spectrum as a function of wind speed and fetch. Using this parametrization a separate wave model is not needed, however, we assume that wind and waves are aligned and the waves are generated only by the local wind, something that is not always the reality (swell waves are not considered). This approach has been used in the past (De Dominicis et al., 2013a, 2014) showing that the addition of this term is almost equivalent to addition of $1 \%$ of the wind velocity and leads to an improvement of the modelled trajectories. If wave model data are available, the Stokes drift can be calculated from wave statistics that can be provided by any wave model: the significant wave height, $H_{S}$, wave mean period, $\bar{T}$, and wave mean direction, $\bar{\phi}$. This is a new MEDSLIK-II feature, recently added during the MEDESS4MS project (Bruciaferri and MEDSLIK-II system team, 2015). The Stokes drift velocity intensity can be then calculated by rewriting Eq. (3) as:

$$
D_{S}(z=0)=\frac{1}{8} \bar{\omega} \bar{k} H_{s}^{2}
$$

where the significant wave height, $H_{s}$, is approximated as four times the square root of the zeroth-order moment of the wave spectrum, the wave mean angular frequency is $\bar{\omega}=\frac{2 \pi}{\bar{T}}$ and the mean wave-number is $\bar{k}=\frac{\bar{\omega}^{2}}{\bar{T}}$ (for deep-water). Thus, the Stokes drift velocity components are:

$$
\begin{aligned}
U_{S} & =D_{S} \cos \bar{\phi} \\
V_{S} & =D_{S} \sin \bar{\phi}
\end{aligned}
$$

where $\phi$ is the wave mean direction provided by wave models. The Stokes drift calculated using bulk (statistically averaged) wave parameters, as in Eq. 4, can result in an underestimation of the Stokes drift induced-current (Tamura et al., 2012). Alternatively, third-generation wave 
models can directly give the surface Stokes drift velocity, i.e. integration of the full wave spectrum done internally by the wave model. Unfortunately, the latter was not implemented by the wave models available in the MEDESS4MS system.

The local wind correction term $\mathbf{U}_{W}$ is written as:

$$
\begin{gathered}
U_{W}=\alpha\left(W_{x} \cos \beta+W_{y} \sin \beta\right) \\
V_{W}=\alpha\left(-W_{x} \sin \beta+W_{y} \cos \beta\right)
\end{gathered}
$$

where $W_{x}$ and $W_{y}$ are the wind zonal and meridional components at $10 \mathrm{~m}$ respectively and $\alpha$ is the percentage of the wind to be considered in the oil slick transport and $\beta$ is the angle of deviation with respect to the currents direction. When $\mathbf{U}_{C}$ is provided by oceanographic models that resolve the upper ocean layer dynamics (with fine vertical resolution and using turbulence closure sub-models), the term $\mathbf{U}_{C}$ contains a satisfactory representation of surface ageostrophic currents and the $\mathbf{U}_{W}$ term may be neglected (in this work $\mathbf{U}_{W}$ has been always set equal to 0 ).

The wind drag velocity, $\mathbf{U}_{D}$, is associated with the leeway (windage) of a floating object, defined as the drift associated with the wind force on the overwater structure of the object. As defined by Breivik et al. (2011) and Röhrs et al. (2012) the leeway-drift velocities can be parametrized as follows:

$$
\mathbf{U}_{D}=\sqrt{\frac{\rho_{a}}{\rho_{w}} \frac{A_{a}}{A_{w}} \frac{C d_{a}}{C d_{w}}} \mathbf{W}=\gamma \mathbf{W}
$$

where $\mathbf{W}$ is the wind velocity at $10 \mathrm{~m}, \rho, A, C_{d}$ are the fluid density, projected areas of the object and drag coefficient, respectively, and subscripts $a$ and $w$ denote the air and seawater environments. The leeway factor $\gamma$ cannot be calculated directly because the drag coefficients $C d_{a}$ and $C d_{w}$ are dependent on Reynolds numbers and are not straightforward to use at the air-sea interface with wave disturbances (Röhrs et al., 2012). However, if we assume $C d_{a}=C d_{w}=1$ (Richardson, 1997) and the density of air and water are considered to be $\rho_{a}=1.29 \mathrm{kgm}^{-3}$ and $\rho_{w}=1025 \mathrm{kgm}^{-3}$, in the particular case of the over-water structure and the submerged part of the object being the same, the parameter $\gamma$ is equal to 0.035 . However, as reported by Breivik et al. (2011) the choice of both drag coefficients to be equal to 1 might not take into account the heave, pitch and roll of open ocean conditions which induce additional viscous damping and drag coefficients are not straightforward to evaluate at the air-sea interface with wave disturbances (Röhrs et al., 2012). Field experiments using SPHERE drifters, performed by Röhrs et al. (2012), suggest to use $\gamma$ in the range $0.003-0.01$.

The last term of Eq. 1 is due to turbulent diffusion and it is parameterized with a random walk scheme as

$$
d \mathbf{x}_{k}^{\prime}(t)=\sqrt{2 \mathbf{K} d t} \vec{Z}
$$

where $\mathbf{K}$ is the turbulent diffusion diagonal tensor and $\vec{Z}$ is a vector of independent random numbers used to model the Brownian random walk processes chosen for the parametrization of turbulent diffusion. The turbulent diffusion is considered to be horizontally isotropic and the three diagonal components of $\mathbf{K}$ are indicated by $K_{h}, K_{h}, K_{v}$. In the simulation experiments of a real oil slick, $K_{h}$ has been set to $2 \mathrm{~m}^{2} \mathrm{~s}^{-1}$, in the range $1-100 \mathrm{~m}^{2} \mathrm{~s}^{-1}$ indicated by ASCE (1996) and De Dominicis et al. (2012), while $K_{v}$ has been set to $0.01 \mathrm{~m}^{2} \mathrm{~s}^{-1}$ in the mixed layer (assumed to be $30 \mathrm{~m}$ deep) and below it to $0.0001 \mathrm{~m}^{2} \mathrm{~s}^{-1}$. When simulating drifter trajectories, $K_{h}$ has been set to $2 \mathrm{~m}^{2} \mathrm{~s}^{-1}$, assuming that in the region there is not any feature that can break the isotropy 
or change dramatically the horizontal diffusivity. The drifter trajectory is assumed to be the barycentre of the particle cloud, while the vertical diffusivity coefficients are set to zero, as the vertical movement of the drifter is not allowed.

When simulating a real oil slick, MEDSLIK-II allows the processes of spreading, evaporation, dispersion, emulsification and coastal adsorption to evolve. When the oil first enters the sea, the slick spreads on the sea surface because of gravitational forces. As it is transported, lighter oil components disappear through evaporation and heavier ones emulsify with the water or are dispersed in the water column. Those processes are modelled by means of bulk formulas that needs the oil volume and density as input, as well as sea surface temperature and wind velocity that are provided by the met-ocean models. In the present version of MEDSLIK-II interactions between oil and waves are not considered. Thus, waves are not considered when modelling the oil dispersion (vertically and horizontally) and waves are not dissipated due to the interaction with the oil. MEDSLIK-II is also able to take into account adsorption of oil by the coast should the slick reach it. The full description of the transformation processes formulation can be found in De Dominicis et al. (2013b). Those processes have been switched off when calculating the drifters' trajectories.

\subsection{Oil spill simulations.}

Starting from the oil slick information acquired by the CSN-2 (see Tab. 1), met-ocean data available through the MEDESS4MS system have been used as input to MEDSLIK-II to predict the position of the oil slick in the next few hours. The initial shapes of the slick are 7 polygons built around the centre coordinates of each oil slick (see Tab. 1). The volumes of each oil slick have been evaluated starting from the areas provided by the CNS-2 system (see Tab. 1) and assuming for each oil patch an average thickness of 35 microns and oil density of $840 \mathrm{~kg} / \mathrm{m}^{3}$. These parameters were chosen, because the oil slick was not observed by satellite the day after, and thus it is realistic to assume that the oil evaporated due to low density (light oil) or/and that the oil slick thickness was too thin to be visible from the satellite. The total amount of oil is then $63 \mathrm{~m}^{3}$.

The meteorological, ocean and wave models available for the SG1 exercise area are listed in Tab. 4, with their spatial coverage and resolution. All the ocean models provided hourly currents fields. Full description of these models is given in Zodiatis et al. (2016). Among this large dataset of models, we decided to force MEDSLIK-II using all the ocean/wave models available in the area and the following two criteria: (1) oil spill simulations are performed using the highest resolution ocean, wave and wind models available (SIM 1 in Tab. 4); (2) oil spill simulations are performed using ocean and wave models that have been forced by the same wind data and thus, representing coherent systems of modelling products (SIM 2 - 5 in Tab. 4). In this first set of simulations currents and waves have been used to advect the oil slick. The Stokes drift has been calculated from wave statistics provided by the wave model, following Eq. 4. The wind has been used only for the calculation of the weathering processes. 


\begin{tabular}{ll}
\hline \hline SIM. & Ocean \\
\hline 1 & PREVIMER MENOR North Western Mediterranean $1.2 \mathrm{~km}$ \\
2 & PREVIMER MENOR North Western Mediterranean $1.2 \mathrm{~km}$ \\
3 & WMED Western Mediterranean $3.5 \mathrm{~km}$ \\
4 & MFS Mediterranean $6.5 \mathrm{~km}$ \\
5 & POSEIDON Mediterranean $10 \mathrm{~km}$ \\
\hline SIM. & Wave \\
\hline 1 & CYCOFOS WAM4 Mediterranean $5 \mathrm{~km}$ \\
2 & PREVIMER MENOR WW3 Western Mediterranean $10 \mathrm{~km}$ \\
3 & MFS WW3 Mediterranean $6.5 \mathrm{~km}$ \\
4 & MFS WW3 Mediterranean $6.5 \mathrm{~km}$ \\
5 & POSEIDON WAM Cycle 4 Mediterranean $10 \mathrm{~km}$ \\
\hline SIM. & Wind \\
\hline 1 & SKIRON Mediterranean $5 \mathrm{~km}$ \\
2 & ARPEGE Mediterranean $10 \mathrm{~km}$ \\
3 & ECMWF Mediterranean $25 \mathrm{~km}$ \\
4 & ECMWF Mediterranean $25 \mathrm{~km}$ \\
5 & POSEIDON Mediterranean $5 \mathrm{~km}$ \\
\hline \hline
\end{tabular}

Table 4: Ocean, wave and wind data used in the MEDSLIK-II oil spill simulations

\subsection{Sensitivity to ocean, waves and wind in drifters simulations}

Drifters deployed into the oil slick on the 17 May 2014 (see Sect. 2.2), have been used to examine how they respond to ocean currents, waves and wind. Four set of simulations have been designed in order to quantitatively evaluate (1) the quality of the currents used, (2) the magnitude of the wave-induced transport, (3) the sensitivity to different Stokes drift parameterizations and (4) the wind drag effect in modeling trajectories of drifters with different immersion depths. Starting from the drifters' deployment positions (Tab. 3), their trajectories have been predicted for 24 hours in the case of CODE and iSPHERE drifters (since the drifters stayed at sea just for 1 day), and for 48 hours in the case of iSLDMB and MAR/GE-T. This allows us to compare the behavior of completely immersed drifters (CODE, iSLDMB) and partially immersed drifters (iSPHERE, MAR/GE- T).

The first set of simulations, listed in Tab. 5, focuses on the evaluation of the surface ocean currents that can be provided by ocean models with different horizontal resolution. In this set of simulations wave and wind advection are not considered.

The second set of simulations, listed in Tab. 6, focuses on the evaluation of the magnitude of the wave-induced transport. The Stokes drift has been calculated from the significant wave height, wave mean period, and wave mean direction (see Eq. 4), provided by wave forecasting systems with different spatial resolution. In order to isolate the effect of the Stokes drift from the ocean currents advection, all the simulations have been forced with the same current field (the highest resolution currents available).

The possibility to calculate the Stokes drift from wave model data has been recently introduced in MEDSLIK-II and it is worthwhile to compare it with the previous method used, the Stokes drift from JONSWAP wave spectrum parameterization (De Dominicis et al., 2013a, 2014) that strongly depends on the wind velocity, as shown in Eq. 3. In all the experiments, the highest resolution currents available have been used, while the wind forcing has been taken from models 
Table 5: List of simulations forced by different surface currents.

\begin{tabular}{lll}
\hline \hline SIM. & $U_{C}$ & $U_{S}$ \\
\hline $1 \mathrm{~S}$ & PREVIMER NW 1.2 km & CYCOFOS MED 5 km \\
$2 \mathrm{~S}$ & PREVIMER NW 1.2 km & MFS-WW3 6.5 km \\
$3 \mathrm{~S}$ & PREVIMER NW 1.2 km & PREVIMER MED 10 km \\
$4 \mathrm{~S}$ & PREVIMER NW 1.2 km & POSEIDON MED $10 \mathrm{~km}$ \\
\hline
\end{tabular}

Table 6: List of simulations forced by surface currents and Stokes drift from wave model output.

\begin{tabular}{lll}
\hline \hline SIM. & $U_{C}$ & $U_{J}$ \\
\hline 1J & PREVIMER NW 1.2 km & SKIRON MED 5 km \\
2J & PREVIMER NW $1.2 \mathrm{~km}$ & POSEIDON MED $5 \mathrm{~km}$ \\
3J & PREVIMER NW $1.2 \mathrm{~km}$ & ARPEGE MED $10 \mathrm{~km}$ \\
4J & PREVIMER NW $1.2 \mathrm{~km}$ & ECMWF $25 \mathrm{~km}$ \\
\hline \hline
\end{tabular}

Table 7: List of simulations forced by surface currents and Stokes drift using JONSWAP formulation based on wind model output.

\begin{tabular}{llll}
\hline \hline SIM. & $U_{C}$ & $U_{S}$ & $U_{D}$ \\
\hline 1D/1D3 & PREVIMER NW 1.2 km & CYCOFOS MED 5 km & SKIRON MED 5 km \\
2D/2D3 & PREVIMER NW 1.2 km & MFS-WW3 6.5 km & SKIRON MED 5 km \\
3D/3D3 & PREVIMER NW 1.2 km & PREVIMER MED 10 km & SKIRON MED 5 km \\
4D/4D3 & PREVIMER NW 1.2 km & POSEIDON MED 10 km & SKIRON MED 5 km \\
\hline \hline
\end{tabular}

Table 8: List of simulations forced by surface currents, Stokes drift from wave model output and wind drag velocity: D is for $1 \%$ leeway factor and D3 is for $3 \%$ leeway factor. 
Two metrics have been used to quantitatively evaluate the accuracy of the drifter trajectory simulations. The first metric is the absolute separation distance $d_{i}\left(\vec{x}_{s}\left(t_{i}\right), \vec{x}_{o}\left(t_{i}\right)\right)$ between the observed and the simulated trajectories, where $d_{i}$ is the distance at the time $t_{i}$ between the simulated drifter position, $\vec{x}_{s}$, and the observed positions, $\vec{x}_{o}$. The second metric is the Liu and Weisberg (2011) skill score. It is defined as an average of the separation distances weighted by the lengths of the observed trajectories:

$$
s\left(t_{i}\right)=1-\frac{1}{n} \frac{\sum_{t=t_{0}}^{t_{i}} d_{i}\left(\vec{x}_{s}(t), \vec{x}_{o}(t)\right)}{\sum_{t=t_{0}}^{t_{i}} l_{o i}\left(\vec{x}_{o}\left(t_{0}\right), \vec{x}_{o}(t)\right)}
$$

where $l_{o i}$ is the length of the observed trajectory at the corresponding time, $t_{i}$, after the deployment time $t_{0}$. Such a weighted average tends to reduce the evaluation errors that may arise using only the absolute separation distance and $n$ is a tolerance threshold. In this work, as suggested by Liu and Weisberg (2011), we used $n=1$, this corresponds to a criterion that cumulative separation distance should not be larger than the associated cumulative length of the drifter trajectory. The higher the $s$ value, the better the performance, with $s=1$ implying a perfect fit between observation and simulation and $s \leq 0$ indicating the model simulations have no skill.

\section{Results}

\subsection{Multi-model simulation of oil slick from satellite}

All the ocean/wave models available from the MEDESS4MS system in the area have been used as input to MEDSLIK-II in order to provide the prediction of the transport of the oil slick observed by the CSN-2 system. The predictions after $3 \mathrm{hrs}$ and $6 \mathrm{hrs}$ have been compared against the oil samples positions (see Tab. 2) and the drifter deployment positions (see Tab. 3), respectively. Fig. 4 shows the MEDSLIK-II predictions forced with the highest resolution forcing fields available in the area of the exercise (SIM 1 in Tab. 4), while Fig. 5 and Fig. 6 show MEDSLIK-II simulations performed using ocean and wave models that have been forced by the same wind data (SIM 2 - 5 in Tab. 4). Only currents and waves have been used to advect the oil slick and the Stokes drift has been calculated from wave statistics provided by the wave model. Wind is used only for calculation of weathering processes

It is possible to observe that the PREVIMER $1.2 \mathrm{~km}$ (SIM1-2) currents (Fig. 4a-b and Fig. 5a-b) and WMED $3.5 \mathrm{~km}$ (SIM3) currents (Fig. 5c-d) are directed north and north-west in the oil slick area, while the MFS $6.5 \mathrm{~km}$ currents (SIM4) are north and north-east and much smaller with respect to the other models (Fig. 6a-b). The POSEIDON $10 \mathrm{~km}$ currents (SIM5) are in the opposite direction with respect to the rest of the models (Fig. 6c-d).

The Stokes drift predicted by CYCOFOS WAM4 (SIM1) is directed south in the oil slick area (Fig. 4a-b). Instead, all the other wave models predict the Stokes drift to the north and north-east direction, but the MFS WW3 Stokes drift is smaller (Fig. 6a-b) compared to the other models. The wind has not been used to advect the oil slick, but only for the transformation processes. Nevertheless, it is interesting to observe that the direction of the local wind does not always correspond with the direction of the Stokes drift. Indeed, the waves are not always generated by local wind conditions and estimating the wave-induced transport just from the wind (for example with JONSWAP), might lead to a wrong estimation of the direction of the Stokes drift.

Although the simulation temporal horizon is short, from Fig. 6 it can be observed that the predictions done with the low resolution $(10 \mathrm{~km})$ POSEIDON currents and waves (SIM 5) do not overlay the oil samples and drifter deployment positions (Fig. 6c-d), while the predicted oil slicks 
by MFS currents and MFS WW3 waves $(6.5 \mathrm{~km})$ (SIM 4) overlay the oil slick predicted positions (Fig. 6a-b), but the latter are not in the higher concentration core of the oil slick. The same is observed in Fig. 4a-b for the simulations performed with the highest resolution forcings available (SIM1: PREVIMER $1.2 \mathrm{~km}$ currents and CYCOFOS WAM4 $5 \mathrm{~km}$ Stokes drift). Instead, for the simulations SIM2 and SIM3 the drifter deployments positions are in the higher concentration core of the oil slick (Fig. 5b-d). SIM1 and SIM2 share the same current forcing (PREVIMER $1.2 \mathrm{~km}$ ), thus the worse performance observed in SIM1 is most probably due to the Stokes drift provided by CYCOFOS WAM4 model. This is of course valid just for this specific case, but it shows that higher resolution not always means higher accuracy.

A more extensive validation of the model performances is done in the next Section through a comparison with drifter trajectories.

\subsection{Impact of ocean currents in modelling drifter trajectories}

Fig. 7-a shows the 2 CODE drifter trajectories overlaid with the simulated trajectories forced with ocean currents with different resolution. It is shown that the lowest resolution currents (POSEIDON MED $10 \mathrm{~km}$ - SIM4C) wrongly reproduce the direction of the currents during the first hours of the simulation, although the correct direction is then recovered, the simulated drifter moves slower than the real one. A general underestimation of the strength of the current is also observed in SIM3C, which is forced by the MFS $6.5 \mathrm{~km}$ currents. The better results are observed with the highest resolution currents available in SIM1C (PREVIMER NW $1.2 \mathrm{~km}$ ) and SIM2C (WMED $3.5 \mathrm{~km}$ ); in both simulations the direction is correct, and in SIM1C the length of the trajectory is comparable with the real one. The above qualitative considerations are confirmed by the absolute separation distance and skill score calculation. Indeed, Fig. 8 shows that separation distance reaches the highest values for the entire simulation period in the case of SIM4C, and the skill score is lower than 0 (no skill) for up to 14 hours of simulation, when the correct direction of the real drifters is finally recovered. SIM3C shows a higher separation distance (and lower skill) than SIM1C and SIM2C, for the entire simulation period. The performance of SIM1C and SIM2C are comparable, although the PREVIMER NW $1.2 \mathrm{~km}$ (SIM1C) seems to perform better toward the end of the simulation period, showing a lower separation distance and higher skill score.

The simulated trajectories of the 2 iSPHERE drifters show the same behavior of the CODE simulated drifter trajectories (indeed the release point of the drifters was few meters apart), as shown in Fig. 7-b. As observed before, higher resolution currents (SIM1C and SIM2C) perform better than low resolution currents (SIM3C and SIM4C). However, the quantitative comparison with the observations shows a higher separation distance and lower skill score than in the case of CODE drifters, see Fig. 8. The separation distance is growing during the entire simulation period, up to $18 \mathrm{~km}$ in case of SIM4C and SIM3C, while in the case of the CODE drifters it reaches a maximum of 7-8 km.

The same considerations can be used in analyzing the iSLDMB and MAR-GE/T simulated trajectories (Fig. 7-c and Fig. 7-d) and the corresponding separation distance and skill score (Fig. 9). The iSLDMB, as expected, shows the same behavior of the CODE drifters, as both are completely submerged, while the MAR-GE/T drifter that is partially overwater behaves similarly to the iSPHERE drifters. The skill score reaches 0.7 in the case of the iSLDMB simulations forced with highest resolution currents (PREVIMER NW $1.2 \mathrm{~km}$ ), while in the case of MAR/GE$\mathrm{T}$ the skill is 0.5 . As it was expected in the case of the iSPHERE and MAR-GE/T, the currents are not sufficient to correctly reproduce the transport of this type of drifters, that may be influenced by the wind on the overwater structure, as better explained in Sect. 4.4. 


\subsection{Impact of waves in modelling drifter trajectories}

Fig. 10 focuses on the effect of waves on the drifter transport. In order to isolate the effect of waves, all the simulations have been performed using the same current field: the highest resolution currents (PREVIMER NW $1.2 \mathrm{~km}$ ), which were shown to perform better in the previous set of simulations. All the simulations indicated by $\mathrm{S}$ (and shown as continuos lines in Fig. 10-11-12) have been performed by adding to the currents the Stokes drift calculated from the wave statistics produced by the wave models with different resolution. Simulations tagged by J (and shown as dashed lines in Fig. 10-11-12) have been performed by adding the Stokes drift calculated by using the JONSWAP spectrum formulation, depending on the wind provided by models with different resolution. By comparing Fig. 10 with Fig. 7, it is evident that by adding the Stokes drift the distance travelled by the simulated drifters is enhanced, this is true for all the drifters, but it is more evident in the 48 hours simulations. As it can be seen in Fig. 10-a and Fig. 10-b and more evidently in Fig. 11, for the first 15 hours the addition of the waves does not produce any effect, since the sea was calm and low wind conditions were experienced. When the wind starts to increase (after 15 hours, see Fig. 13), the effect of the waves become visible on the simulated drifter paths. From the last few hours of the CODE and iSPHERE trajectories (see Fig. 11), it seems that the addition of Stokes drift-JONSWAP perform better than the Stokes drift from wave model statistics, and this is true for both type of drifters. However, much more information can be extracted by the 48 hours simulated trajectories.

Fig. 12 shows that for up to 30 hours the simulations with JONSWAP performs better than the one with the Stokes drift from the wave models, but it is not possible to find any clear connection with the resolution of the wind models. Indeed, it seems that higher resolution winds SIM1J and SIM2J (SKIRON MED 5km and POSEIDON MED $5 \mathrm{~km}$ ) show lower separation distance (higher skill score) than the lower resolution winds SIM3J and SIM4J (ARPEGE $10 \mathrm{~km}$ and ECWMF $25 \mathrm{~km}$ ). In the case of the Stokes drift from the wave models, up to 30 hours, the performance is not connected with the model resolution, but for all simulations the separation distance and skill score are better than with the transport driven just by the ocean currents (the grey line in Fig. 10-11-12). The above considerations are valid for both iSLDMB and MARGE/T drifters.

In Fig. 12 it is interesting to observe what happens when the wind continues to increase. After 30 hours from the drifters' deployment high wind speeds are experienced (see Fig. 13) and in the case of the iSLDMB drifters the separation distance is higher by using JONSWAP than with Stokes drift from wave model data. The separation distance decreases with higher resolution wind models (lower separation distance with SIM1J - SKIRON MED $5 \mathrm{~km}$ and SIM2J POSEIDON MED $5 \mathrm{~km}$ ), as confirmed also by the skill score. Apart from SIM3S (PREVIMER MED $10 \mathrm{~km}$ ), all the wave models show a comparable performance, as it showed by the skill score trend. In the case of MAR-GE/T the separation distance is always lower by using the JONSWAP spectrum parameterization. By looking to the skill score, no correlation is found between the wind resolution and the simulations' accuracy. In the case of the Stokes drift parameterizations, it seems that SIM3S perform better than the other wave models.

From the above comparison what is evident is that in high wind speed conditions, the addition of the Stokes drift calculated by the JONSWAP parameterization leads to an overestimation of the displacement of the iSLDMB, thus leading to worse performance. The addition of the Stokes drift from wave model statistics performed better, but is difficult to conclude which is the model with the highest accuracy. In low wind conditions, the addition of the Stokes drift calculated by JONSWAP leads to better results, compensating for the underestimation of the ocean currents. 
When this compensation is too high due to high wind speeds, this simple additive correction does not work. In the case of the MAR-GE/T the addition of the Stokes drift calculated by JONSWAP always leads to better results, in this case the overestimation of the Stokes drift does not compensate only for the underestimation of the ocean currents, but also might fill the gap of the missing wind drag process, as it is shown in the next Section.

\subsection{Impact of wind drag in modelling drifter trajectories}

Fig. 14 shows the effect of the wind drag on the different types of drifters. In order to evaluate the effect of the wind and to be able to compare the results with the simulations performed using the Stokes drift from wave model data, the same ocean and wave forcing have been used, with the addition of the wind drag velocity calculated from the highest resolution wind model available. As discussed in the previous Section, the JONSWAP parameterization may lead in same cases to better results than the Stokes drift from wave model output. However, the JONSWAP parameterization simply relies on the wind velocity by assuming that wind and waves are aligned and that the waves are generated only by the local wind, something that is not always the reality (swell is not considered). Thus, we believe it is more correct to use the Stokes drift from wave model output. Since we want to focus on the effect of wind in modelling different kinds of drifters, we chose to force all the simulations with the highest resolution wind model available, although in the simulations using JONSWAP it was not possible to determine which wind model performs better.

We tested the addition to the currents and Stokes drift of $1 \%(\gamma=0.01)$ and $3 \%(\gamma=0.03)$ of the wind velocity in the direction of the wind. As shown in Fig. 14, when the wind drag velocity is added to the currents and waves, the simulated drifters transport direction is deviated in the direction of the wind. During the first 15 hours of simulation, this effect is not evident due to the low wind velocity (see Fig. 13). However, as it can be observed in Fig. 15, during the last hours of the simulation the addition of the wind drag velocity leads to an increase of the separation distance in the case of the CODE drifters, which is more evident when using a $3 \%$ leeway factor. On the other hand, the iSPHERE drifters present a decrease of the separation distance when adding the wind drag velocity and with $3 \%$ leeway factor the separation distance is lower than with $1 \%$. As described in Sect. 3.1, in the particular case of the over-water structure and the submerged part of the object being the same, as in the case of the iSPHERE drifter, the parameter $\gamma$ can indeed be equal to 0.035 .

The wind drag effect can be better evaluated on the 48 hours drifter simulations. As can be observed in Fig. 14-d, the addition of the wind deviates the MAR-GE/T simulated drifters in the direction of the real drifter path, which is very evident with a $3 \%$ leeway factor, while this deviation is not needed for the iSLDMB drifters. As shown in Fig. 16, the simulation with 3\% leeway factor performs worse for the iSLDMB after 15 hours, i.e. when the wind velocity starts to increase. On the other hand, up to 30 hours the simulations with $1 \%$ leeway factor perform better for both iSLDMB and MAR-GE/T drifters. However, after 30 hours when the wind starts to further increase (see Fig. 13), in the case of the iSLDMB the addition of the $1 \%$ or $3 \%$ leeway factor produces a decrease of the skill score (and increase of the separation distance), while in the case of the MAR-GE/T the skill score is higher when considering the wind drag velocity. It should be noted, that in this specific case study, the final change in direction of the MAR-GE/T observed drifters' path (see Fig. 14-d) is not reproduced by any ocean, wave or wind model, thus leading to a general worsening of the performances toward the end of the simulation period.

As was observed for the Stokes drift JONSWAP parameterization, in the case of low wind conditions the addition of the wind drag velocity with $1 \%$ leeway factor leads to better results 
with all types of drifters. This might be due to an enhancement of the drifters' displacement, that is underestimated by using only the ocean currents and waves. The effect of the wind-driven sea surface currents and subsurface turbulence might not be adequately resolved by most oceanographic models in the uppermost centimeter of water column, leading to an underestimation of the the actual wind induced surface current. However, in the case of high wind speed and/or 3\% leeway factor, it is evident that the addition of the wind drag velocity leads to a deviation of the simulated drifters in the direction of the wind that does not happen in the real trajectories of the fully submerged drifters (iSLDMB).

\section{Conclusions}

During the 10 days of MEDESS4MS Serious Game 1 exercise, one of the oil slicks that were observed by satellite was effectively found at sea. Samples of oil were collected and drifters with different water-following characteristics were deployed into the oil slick. Although we did not succeed in the collection of a time series of satellite observations of the same oil slick to be compared with the drifter trajectories, the oil slick in-situ observations and drifter trajectories have been used to evaluate the quality of the ocean, wave and meteorological models forecasts that are accessible from the MEDESS4MS system.

MEDSLIK-II predictions of the oil slick evolution, using different combinations of oceanwave-meteorological models, have been compared with the oil observations at sea $3 \mathrm{hrs}$ and 6 hrs after the simulation start. Although the simulation temporal horizon is short, we found that low resolution ocean data perform worse than higher resolution ocean models. The same was found from the analysis of the behavior of different types of drifters at sea: all drifters are better reproduced by using higher resolution ocean models. The final objective of this comparison was not to determine which model is the best among the others, but was to show that we should deal with the uncertainties generated by different model outputs. A multi-model approach can help to quantify uncertainties related to the met-ocean fields. When all the models are in agreement, we might be more confident in the accuracy of the forecasts, on the other hand they might also be all affected by the same error. It is thus difficult to deal with different model outputs without an objective method of analyzing them. Very few examples are available on using met-ocean ensembles in Lagrangian trajectory models (Vandenbulcke et al., 2009; Scott et al., 2012; Wei et al., 2013). Those studies demonstrated that the ensemble can generate important uncertainty information, in addition to predicting the trajectory with higher accuracy than a single ocean model forecast. In the future, a method to weight available ocean/met/wave/oil spill forecasts against validation metrics in order to provide an estimate of the confidence level of each member of the multi-model ensemble has to be developed. The final aim has to be a tool that will be able to compile all the collected results from the different models and produce a synthetic output (such as the probability density charts), that could be used by the end-users.

Drifters are the most common instruments used for validation of oil spill and/or trajectory models; this study highlighted that we must carefully consider which kind of drifters we are using to validate trajectory simulations, in order to add the correct terms in the trajectory transport equation. All CODE-type drifters (two CODEs and one iSLDMB) are completely submerged and have the same behavior at sea, shown to be mainly driven by surface ocean currents. While one MAR/GE-T and two iSPHERE, that are partially emerged, move similarly and we found that the surface ocean currents are not sufficient to correctly reproduce their transport. It is worth pointing out that two CODE drifters were moving together, and likewise for the two iSPHERE drifters. This allows us to be more confident in saying that the different behavior is due to the 
different drifter shapes, rather than to sub-mesoscale ocean dynamics. From the analysis of the behavior of different type of drifters at sea, we found that all drifter trajectories are better reproduced by using higher resolution ocean models. The Stokes drift generally enhances the simulated drifter displacements. We found that the JONSWAP parameterization for Stokes drift calculation leads to an overestimation of the displacement, particularly evident with CODE-type drifters and in high wind speed conditions. This overestimation is not evident in the MAR/GE-T and iSPHERE drifters, since it is probably masked by the missing wind drag effect acting on the overwater drifter structure. We found that in the case of low wind conditions the addition of wind drag velocity with $1 \%$ or $3 \%$ leeway factor leads to better results with all type of drifters. We think that is not due to a real direct wind drag acting on the drifters, but it is most probably due an incorrect reproduction of the wind-driven sea surface currents and subsurface turbulence at the ocean surface by oceanographic models. This is due to resolution constraints, since surface currents provided by an ocean model are actually the currents in the top meter of the water column and due to missing physics describing the mixed turbulent layer at the air/sea interface. On the other hand the addition of a wind drag velocity with $1 \%$ or $3 \%$ leeway factor in high wind speed conditions leads to a lower skill in the case of submerged drifters (CODE or iSLDMB), while MAR/GE-T and iSPHERE generally are better reproduced with a higher leeway factor. Indeed, we found that the addition of the wind drag velocity leads to a deviation of the simulated drifters in the direction of the wind that has been found to affect only the partially emerged drifters, while the wind drag effect does not affect the fully submerged drifters. This is more evident in high wind speed conditions.

In the future it might be interesting to further explore the wave-induced transport term. First, the effect of having the Stokes drift calculated by integration of the full wave spectrum done internally by the wave model, instead of obtaining it a posteriori from bulk wave parameters, should be examined. As shown by Tamura et al. (2012), this might enhance the magnitude of the Stokes drift. Second, by using fully coupled wave-hydrodynamic models it will be worth to estimate the effect of wave-induced currents (Smith, 2006; McWilliams et al., 2004; Mellor, 2003, 2008; Ardhuin et al., 2008) on tracer transport.

In the future, further experiments are still needed to assess which drifter behaves most similarly to an oil slick and under which ocean currents and wind conditions. However, oil slicks do not resemble objects with an overwater structure, that feel that wind drag effect and, thus, we may believe oil slicks would behave more like submerged drifters. On the other hand, an oil slick at the air/sea interface is driven by the currents in the top millimeters of the water column, which are certainly linked with wind and wave-induced turbulence, which are still poorly understood and further fundamental research is needed to achieve a full comprehension of the processes acting at the air/sea interface.

\section{Acknowledgments}

This work has been funded by MEDESS4MS Project (Mediterranean Decision Support System for Marine Safety, Ref. 2S-MED11-01) co-financed by the European Regional Development Fund through the MED Programme. Authors are grateful to the Italian Coast Guard for having made available vessels, aircraft, satellite images and logistics support during the Serious Games 1 exercise. We thank Piero Zuppelli (OGS) for supporting the operations at sea and drifter deployments. 


\section{References}

Abascal, A., Castanedo, S., Mendez, F., Medina, R., Losada, I., 2009. Calibration of a Lagrangian transport model using drifting buoys deployed during the Prestige oil spill. Journal of Coastal Research 25.

Al-Rabeh, A., 1994. Estimating surface oil spill transport due to wind in the Arabian Gulf. Ocean Engineering 21, 461-465.

Al-Rabeh, A.H., Lardner, R.W., Gunay, N., 2000. Gulfspill Version 2.0: a software package for oil spills in the Arabian Gulf. Environmental Modelling and Software 15, 425-442.

Ardhuin, F., Rascle, N., Belibassakis, K.A., 2008. Explicit wave-averaged primitive equations using a generalized lagrangian mean. Ocean Modelling 20, 35-60.

ASCE, 1996. State-of-the-Art Review of modeling transport and fate of oil spills. Journal of Hydraulic Engineering 122, 594-609.

Breivik, Ø., Allen, A.A., Maisondieu, C., Roth, J.C., 2011. Wind-induced drift of objects at sea: The leeway field method. Applied Ocean Research 33, 100-109.

Brostrom, G., Carrasco, A., Daniel, P., Hackett, B., Lardner, R., Panayidou, X., Paradis, D., Zodiatis, G., 2008. Comparison of different oil drift models and different ocean forcing with observed drifter trajectory in the Mediterranean, in: Coastal to Global Operational Oceanography: Achievements and challenges, 5th EuroGoos Conference proceedings.

Bruciaferri, D., MEDSLIK-II system team, 2015. MEDSLIK-II, Lagrangian marine surface oil spill model, User Manual, Version 1.02. Rapporti Tecnici INGV

Caballero, A., Espino, M., Sagarminaga, Y., Ferrer, L., Uriarte, A., González, M., 2008. Simulating the migration of drifters deployed in the Bay of Biscay, during the Prestige crisis. Marine pollution bulletin 56, 475-482.

Carracedo, P., Torres-López, S., Barreiro, M., Montero, P., Balseiro, C., Penabad, E., Leitao, P., Pérez-Muñuzuri, V., 2006. Improvement of pollutant drift forecast system applied to the Prestige oil spills in Galicia Coast (NW of Spain): Development of an operational system. Marine pollution bulletin 53, 350-360.

Coppini, G., De Dominicis, M., Zodiatis, G., Lardner, R., Pinardi, N., Santoleri, R., Colella, S., Bignami, F., Hayes, D.R., Soloviev, D., Georgiou, G., Kallos, G., 2011. Hindcast of oil-spill pollution during the Lebanon crisis in the Eastern Mediterranean, July-August 2006. Marine Pollution Bulletin 62, 140-153.

Cucco, A., Sinerchia, M., Ribotti, A., Olita, A., Fazioli, L., Perilli, A., Sorgente, B., Borghini, M., Schroeder, K., Sorgente, R., 2012. A high-resolution real-time forecasting system for predicting the fate of oil spills in the Strait of Bonifacio (western Mediterranean Sea). Marine Pollution Bulletin

Davis, R.E., 1985. Drifter observations of coastal surface currents during CODE: the method and descriptive view. Journal of Geophysical Research 90, 4741-4755.

De Dominicis, M., Falchetti, S., Trotta, F., Pinardi, N., Giacomelli, L., Napolitano, E., Fazioli, L., Sorgente, R., Haley Jr, P.J., Lermusiaux, P.F., et al., 2014. A relocatable ocean model in support of environmental emergencies. Ocean Dynamics 64, 667-688.

De Dominicis, M., Leuzzi, G., Monti, P., Pinardi, N., Poulain, P.M., 2012. Eddy diffusivity derived from drifter data for dispersion model applications. Ocean Dynamics 62, 1381-1398.

De Dominicis, M., Pinardi, N., Zodiatis, G., Archetti, R., 2013a. MEDSLIK-II, a Lagrangian marine surface oil spill model for short-term forecasting-Part 2: Numerical simulations and validations. Geoscientific Model Development 6, 1871-1888.

De Dominicis, M., Pinardi, N., Zodiatis, G., Lardner, R., 2013b. MEDSLIK-II, a Lagrangian marine surface oil spill model for short-term forecasting-Part 1: Theory. Geoscientific Model Development 6, 1851-1869.

Hasselmann, K., Barnett, T., Bouws, E., Carlson, H., Cartwright, D., Enke, K., Ewing, J., Gienapp, H., Hasselmann, D., Kruseman, P., Meerburg, A., Mller, P., Olbers, D., Richter, K., Sell, W., Walden, H., 1973. Measurements of windwave growth and swell decay during the Joint North Sea Wave Project (JONSWAP). Ergnzungsheft zur Deutschen Hydrographischen Zeitschrift Reihe, A8-12.

Liu, Y., Weisberg, R.H., 2011. Evaluation of trajectory modeling in different dynamic regions using normalized cumulative lagrangian separation. J. Geophys. Res. 116-C09013.

Liu, Y., Weisberg, R.H., Hu, C., Zheng, L., 2011. Trajectory forecast as a rapid response to the Deepwater Horizon oil spill, in Monitoring and Modeling the Deepwater Horizon Oil Spill: A Record-Breaking Enterprise. Geophys. Monogr. Ser. 195, 153-165.

Liubartseva, S., De Dominicis, M., Oddo, P., Coppini, G., Pinardi, N., Greggio, N., 2015. Oil spill hazard from dispersal of oil along shipping lanes in the southern adriatic and northern ionian seas. Marine pollution bulletin 90, $259-272$.

Mariano, A., Kourafalou, V., Srinivasan, A., Kang, H., Halliwell, G., Ryan, E., Roffer, M., 2011. On the modeling of the 2010 Gulf of Mexico Oil Spil. Dynamics of Atmospheres and Oceans

McWilliams, J.C., Restrepo, J.M., Lane, E.M., 2004. An asymptotic theory for the interaction of waves and currents in coastal waters. Journal of Fluid Mechanics 511, 135-178.

Mellor, G.L., 2003. The three-dimensional current and surface wave equations. Journal of Physical Oceanography 33, 1978-1989. 
Mellor, G.L., 2008. The depth-dependent current and wave interaction equations: a revision. Journal of Physical Oceanography 38, 2587-2596.

Pisano, A., 2016. -. Deep Sea Research Part II .

Poulain, P.M., 1999. Drifter observations of surface circulation in the Adriatic Sea between December 1994 and March 1996. J. Mar. Syst.

Price, J.M., Reed, M., Howard, M.K., Johnson, W.R., Ji, Z.G., Marshall, C.F., Guinasso, N.L., et al., 2006. Preliminary assessment of an oil-spill trajectory model using satellite-tracked, oil-spill-simulating drifters. Environmental Modelling \& Software 21, 258-270.

Reed, M., Turner, C., Odulo, A., 1994. The role of wind and emulsification in modelling oil spill and surface drifter trajectories. Spill Science \& Technology Bulletin 1, 143-157.

Richardson, P.L., 1997. Drifting in the wind: leeway error in shipdrift data. Deep Sea Research Part I: Oceanographic Research Papers 44, 1877-1903.

Röhrs, J., Christensen, K.H., Hole, L.R., Broström, G., Drivdal, M., Sundby, S., 2012. Observation-based evaluation of surface wave effects on currents and trajectory forecasts. Ocean Dynamics 62, 1519-1533.

Sayol, J., Orfila, A., Simarro, G., Conti, D., Renault, L., Molcard, A., 2014. A Lagrangian model for tracking surface spills and SaR operations in the ocean. Environmental Modelling Software 52, $74-82$.

Scott, R.B., Ferry, N., Drévillon, M., Barron, C.N., Jourdain, N.C., Lellouche, J.M., Metzger, E., Rio, M., Smedstad, O.M., 2012. Estimates of surface drifter trajectories in the equatorial atlantic: a multi-model ensemble approach. Ocean dynamics 62, 1091-1109.

Smith, J.A., 2006. Wave-current interactions in finite depth. Journal of Physical Oceanography 36, 1403-1419.

Sotillo, M., Alvarez Fanjul, E., Castanedo, S., Abascal, A., Menendez, J., Emelianov, M., Olivella, R., García-Ladona, E., Ruiz-Villarreal, M., Conde, J., Gǿomez, M., Conde, P., Gutierrez, A., Medina, R., 2008. Towards an operational system for oil-spill forecast over Spanish waters: Initial developments and implementation test. Marine Pollution Bulletin 56, 686-703.

Stokes, G., 1847. On the theory of oscillatory waves. Trans Cambridge Philos Soc 8, 441-473.

Tamura, H., Miyazawa, Y., Oey, L.Y., 2012. The stokes drift and wave induced-mass flux in the north pacific. Journal of Geophysical Research: Oceans (1978-2012) 117.

Vandenbulcke, L., Beckers, J.M., Lenartz, F., Barth, A., Poulain, P.M., Aidonidis, M., Meyrat, J., Ardhuin, F., Tonani, M., Fratianni, C., Torrisi, L., Pallela, D., Chiggiato, J., Tudor, M., Book, J., Martin, P., G., P., Rixen, M., 2009. Super-ensemble techniques: Application to surface drift prediction. Progress in Oceanography 82, 149-167.

Wei, M., Jacobs, G., Rowley, C., Barron, C.N., Hogan, P., Spence, P., Smedstad, O., Martin, P., Muscarella, P., Coelho, E., 2013. The performance of the US Navy's RELO ensemble, NCOM, HYCOM during the period of GLAD at-sea experiment in the Gulf of Mexico. Deep Sea Research Part II: Topical Studies in Oceanography .

Zodiatis, G., Dominicis, M.D., Perivoliotis, L., Radhakrishnan, H., Georgoudis, E., Sotillo, M., Lardner, R.W., Krokos, G., Bruciaferri, D., Clementi, E., Guarnieri, A., Ribotti, A., Drago, A., Bourma, E., Padorno, E., Daniel, P., Gonzalez, G., Chazot, C., Gouriou, V., Kremer, X., Sofianos, S., Tintore, J., Garreau, P., Pinardi, N., Coppini, G., Lecci, R., Pisano, A., Sorgente, R., Fazioli, L., Soloviev, D., Stylianou, S., Nikolaidis, A., Panayidou, X., Karaolia, A., Gauci, A., Marcati, A., Caiazzo, L., Mancini, M., 2016. The mediterranean decision support system for marine safety dedicated to oil slicks predictions. Deep Sea Research Part II .

Zodiatis, G., Hayes, D., Lardner, R., Georgiou, G., Kallos, G., Sofianos, S., Pinardi, N., Panayidou, X., 2010. Marine core and downstream oceanographic services in the Eastern Mediterranean Levantine Basin and their success in assisting the EU response agencies, in: Coastal to Global Operational Oceanography: Achievements and challenges, EuroGoos Conference proceedings, pp. 465-472. 
685 Figures

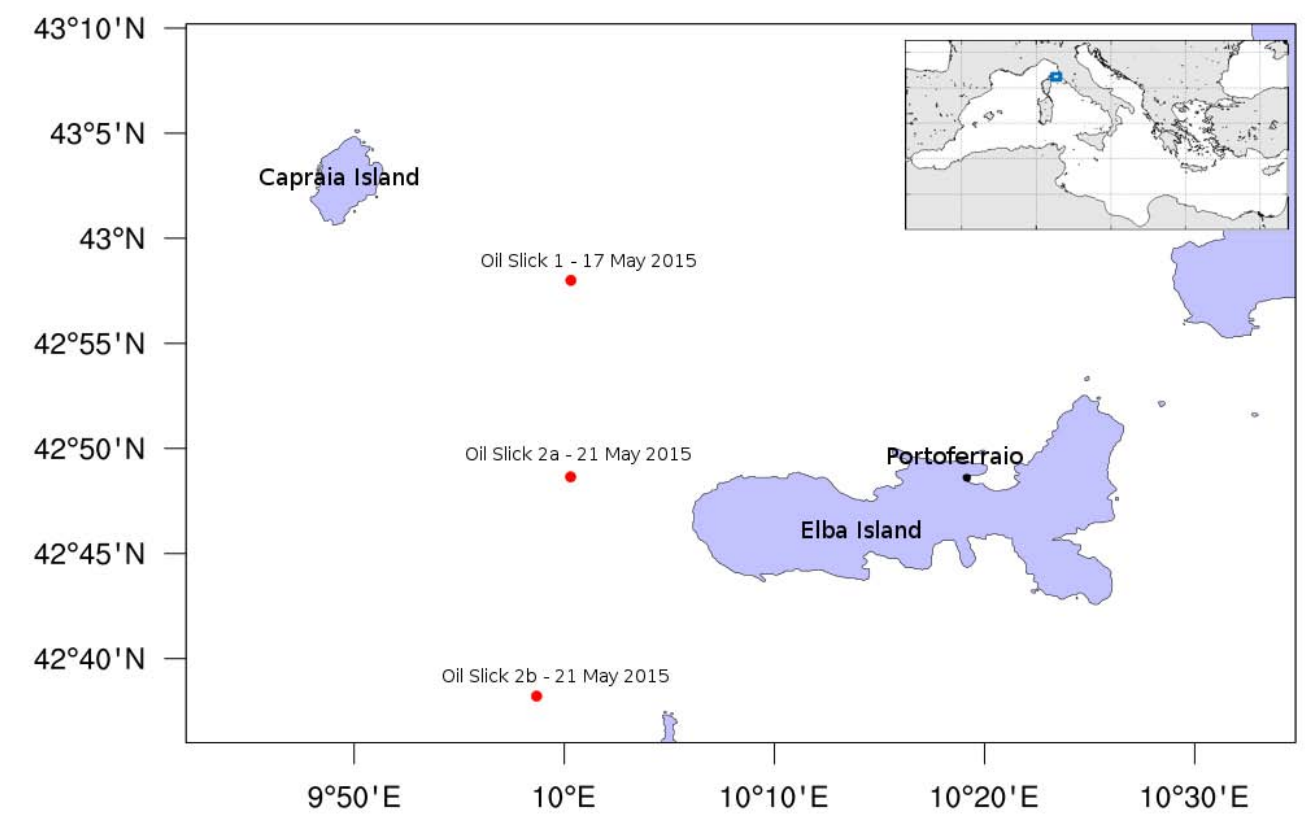

Figure 1: MEDESS4MS Serious Game 1 (SG1) exercise area, Elba Island region, Western Mediterranean Sea (red dots are the positions of the oil slicks observed by satellite during the exercise period). 

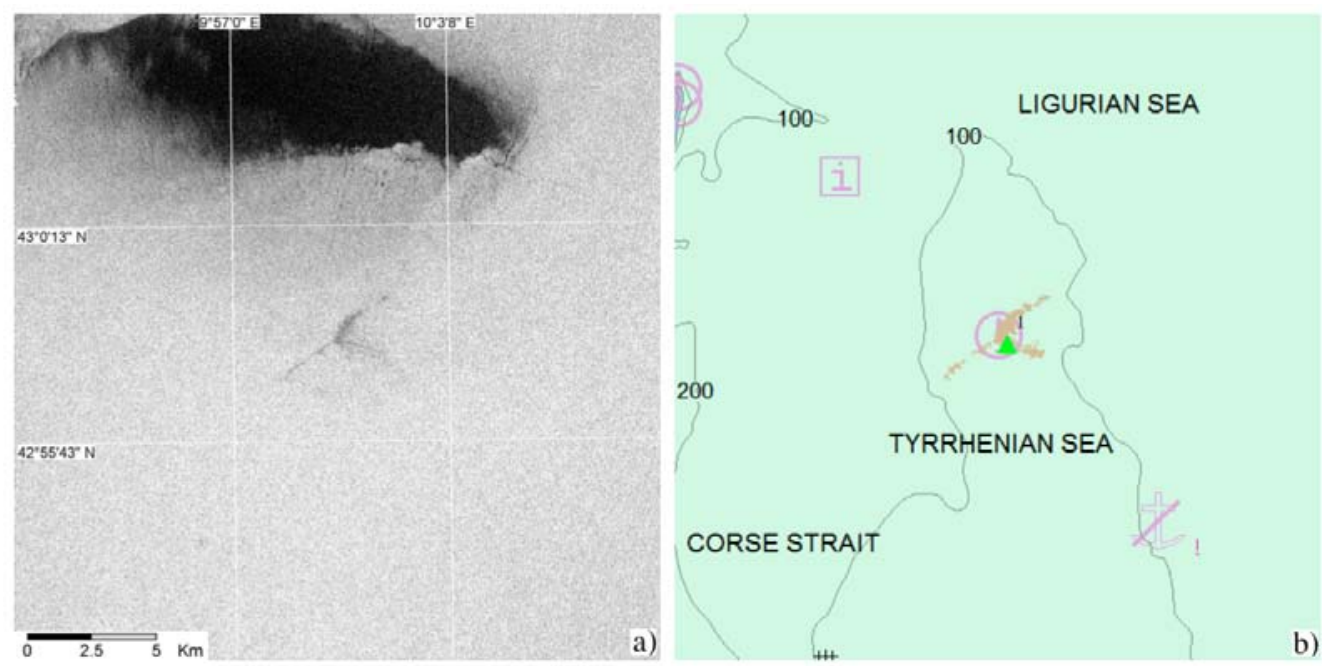

Figure 2: Initial position of the oil slick observed by satellite on the 17th of May 2014 at 05:38 UTC, from EMSA Clean Sea Net alert report received by ITCG. Panel a shows the original satellite image. Panel $b$ is the output of the CSN-2 automatic detection algorithm (the green triangle is the oil slick barycentre).
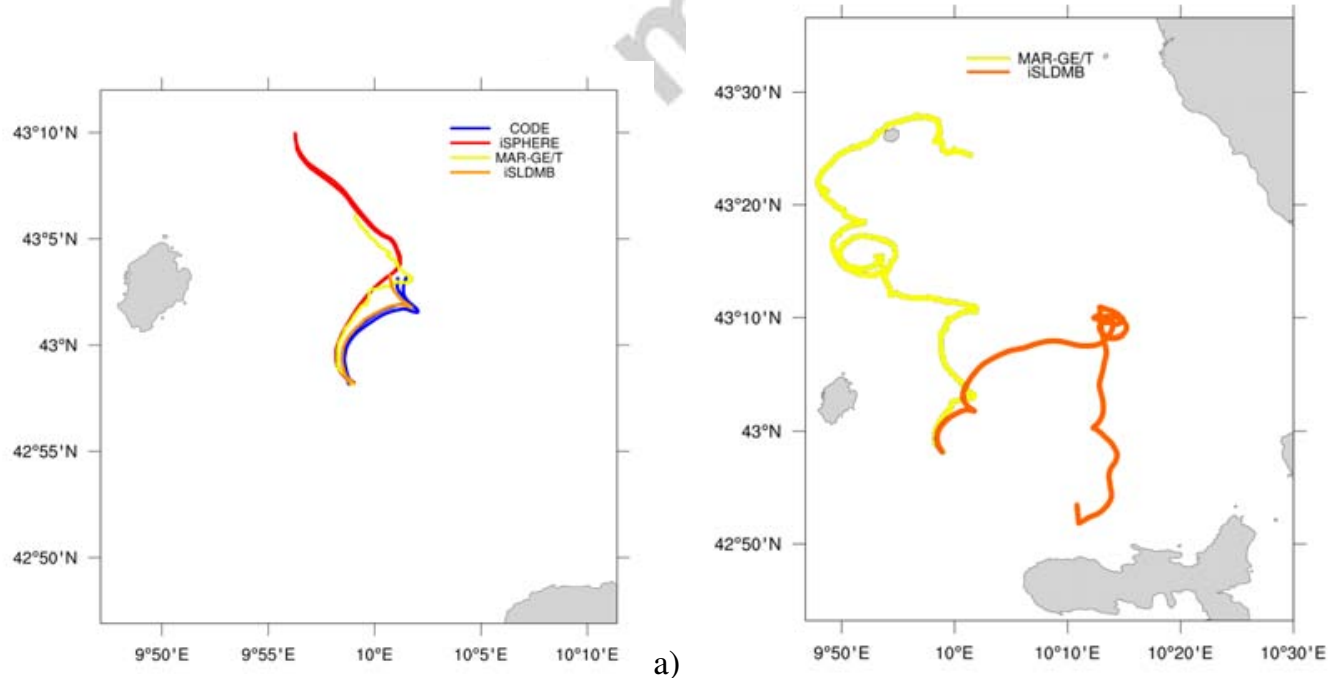

b)

Figure 3: Observed trajectories of the drifters deployed on the 17 May 2014: 2 iSPHERE (red lines) 2 CODE (blue lines), iSLDMB (orange line) and MAR-GE/T (yellow line). Panel a shows the trajectories after 1 day at sea. Panel $b$ shows the trajectories after 7 days at sea (only iSLDMB and MAR-GE/T, since iSPHEREs and CODEs have been recovered after 1 day). 

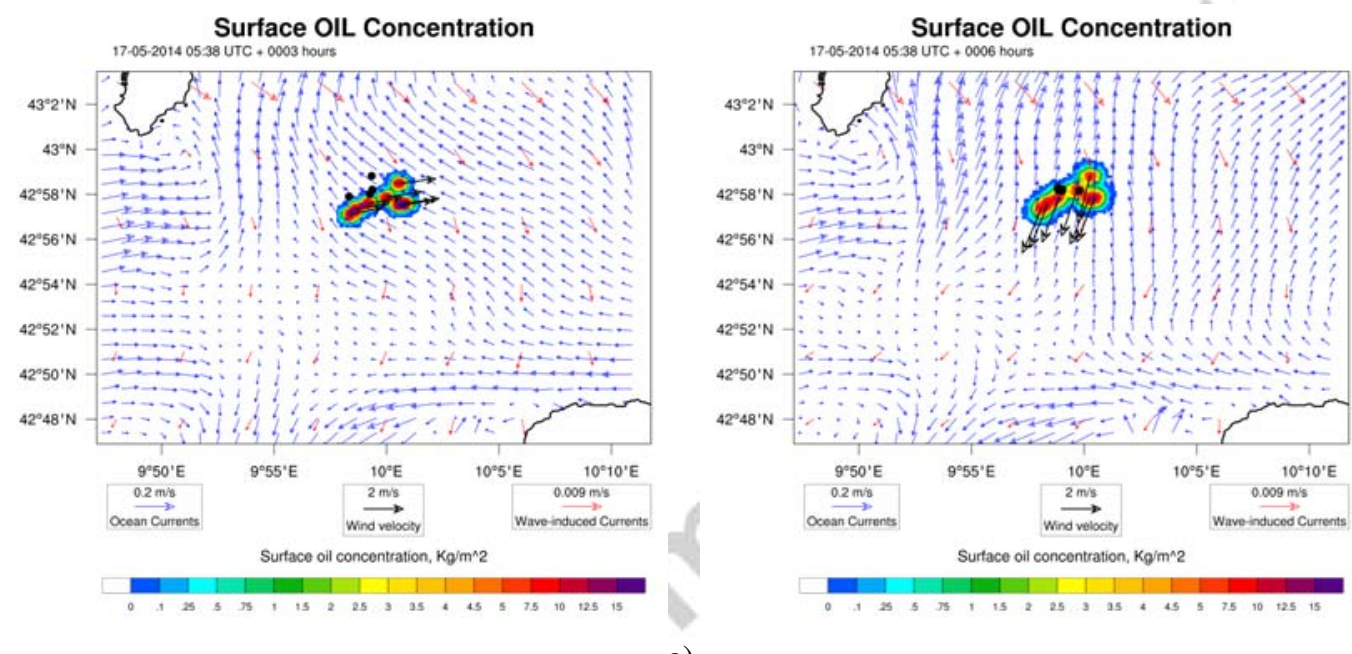

a)

b)

Figure 4: MEDSLIK-II oil slick simulated position performed with the highest resolution forcings available in the area: surface currents from PREVIMER NW $1.2 \mathrm{~km}$, Stokes drift from CYCOFOS WAM4 $5 \mathrm{~km}$, winds from SKIRON $5 \mathrm{~km}$. The predicted oil slick positions are compared with in-situ oil sampling positions (black dots in panels a) collected after 3 hours from satellite observations and drifter deployment positions after 6 hours from satellite observations (black dots in panels b). Wind is used only for calculation of weathering processes. 

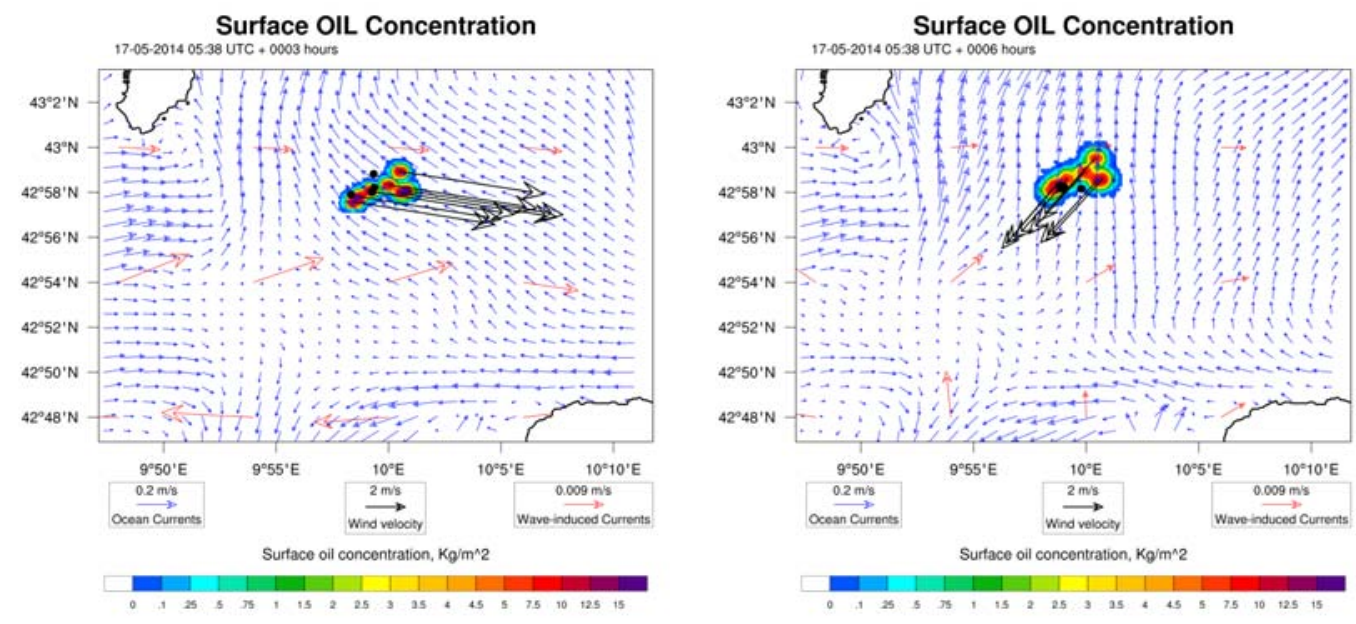

a)
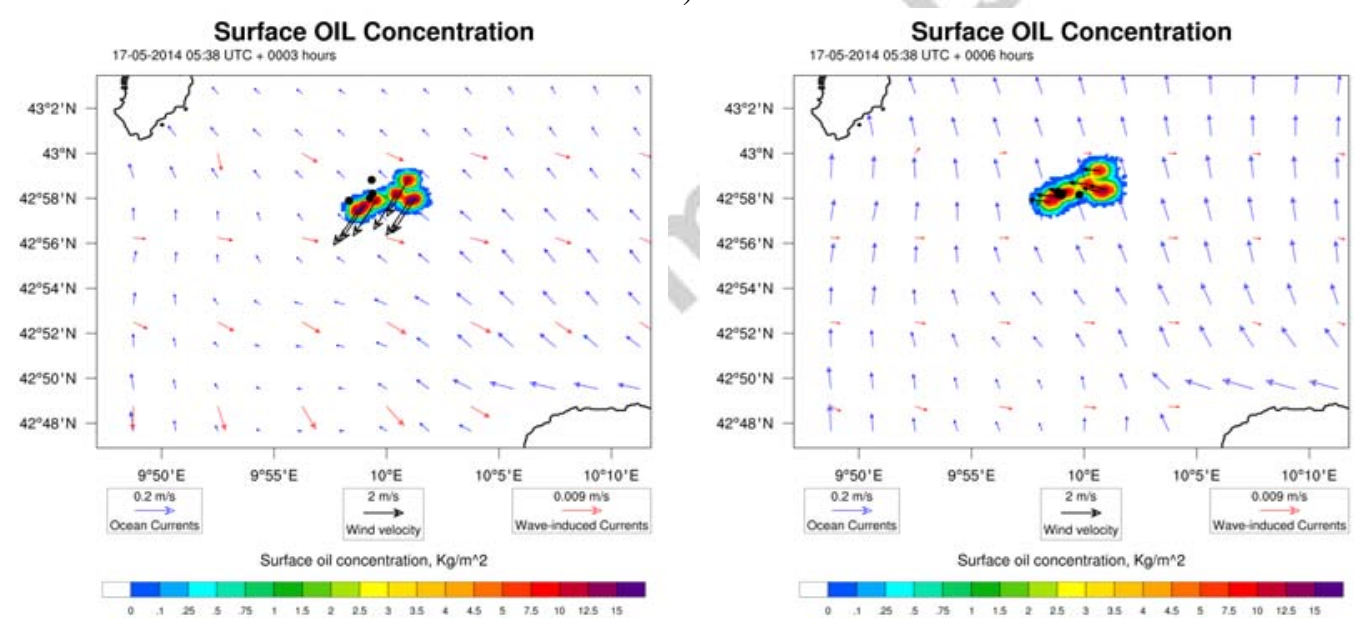

c)

Figure 5: MEDSLIK-II oil slick simulated position compared with in-situ oil sampling positions (black dots in panels a,c) collected after 3 hours from satellite observations and drifter deployment positions after 6 hours from satellite observations (black dots in panels b,d). Panel a-b: simulations have been performed using surface currents from PREVIMER NW $1.2 \mathrm{~km}$, Stokes drift from PREVIMER MED $10 \mathrm{~km}$, winds from ARPEGE MED $10 \mathrm{~km}$; Panel c-d: simulations have been performed using surface currents from WMED $3.5 \mathrm{~km}$, Stokes drift from MFS-WW3 $6.5 \mathrm{~km}$, winds from ECMWF $25 \mathrm{~km}$. Wind is used only for calculation of weathering processes. 


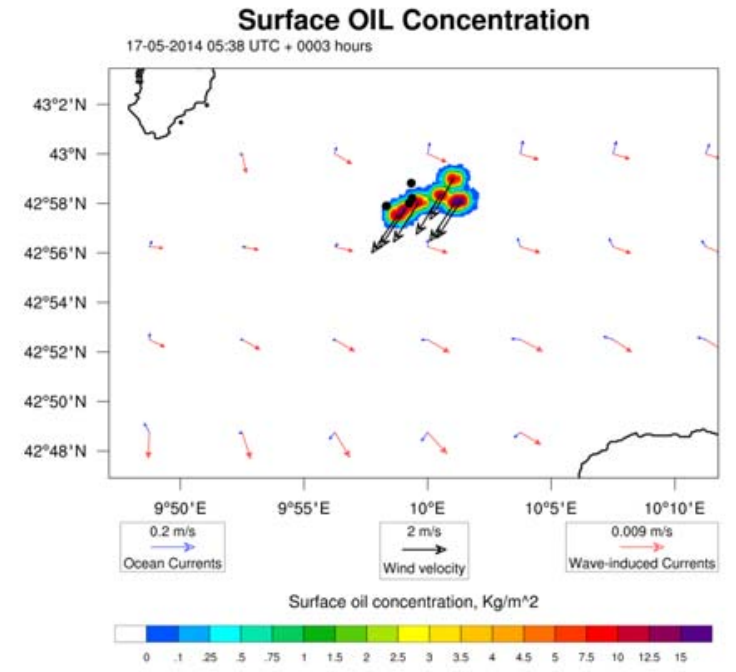

a)

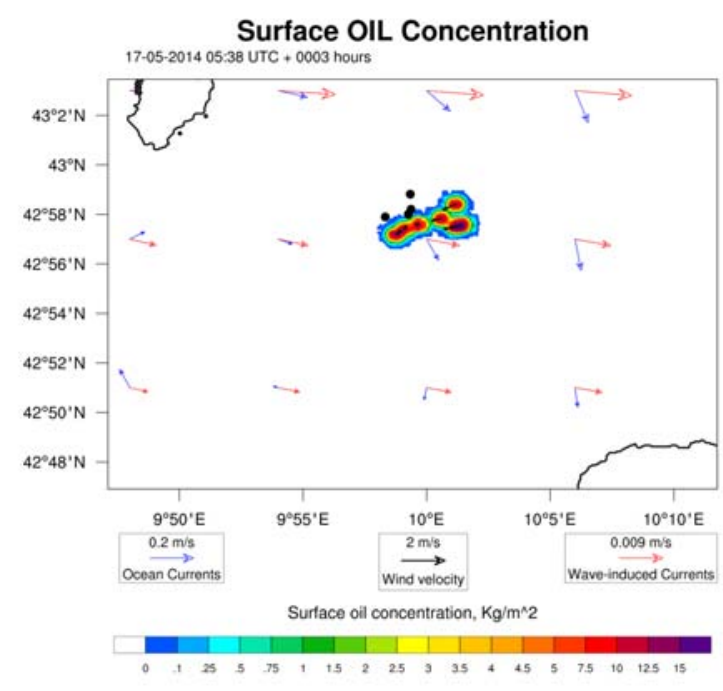

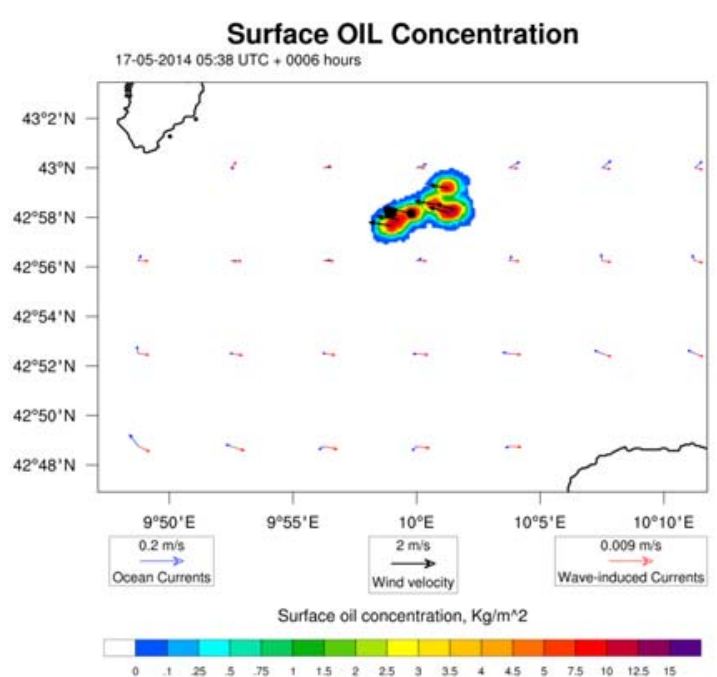

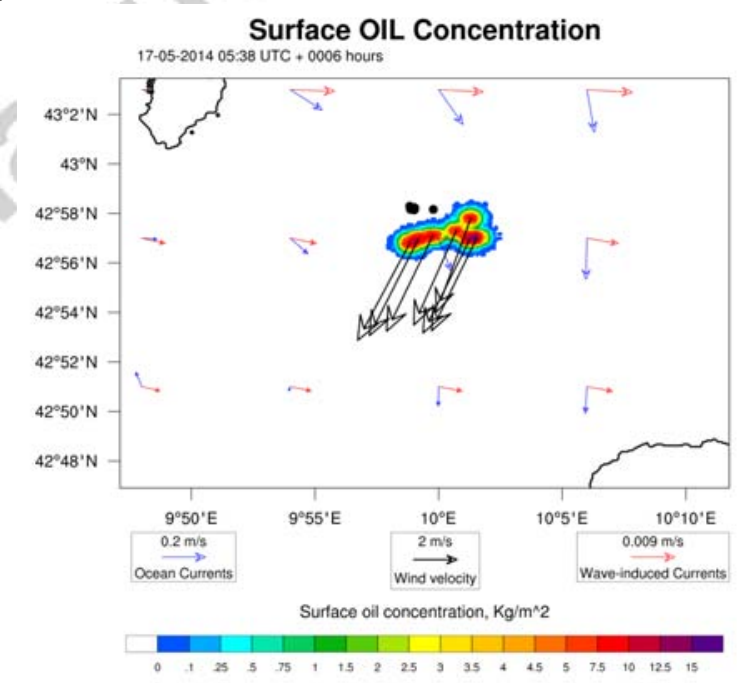

c) b) 
CODE

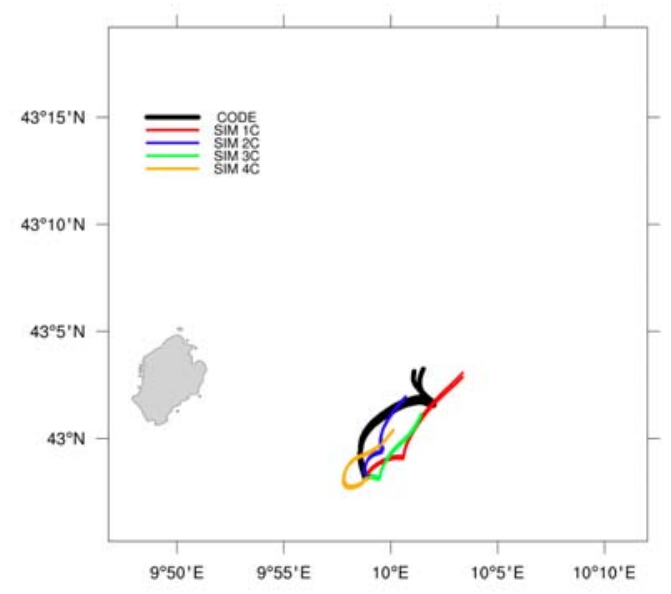

iSLDMB

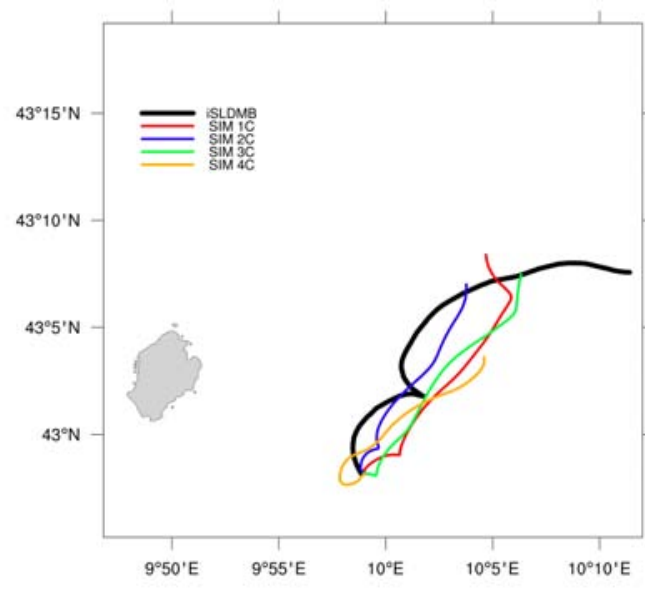

ISPHERE

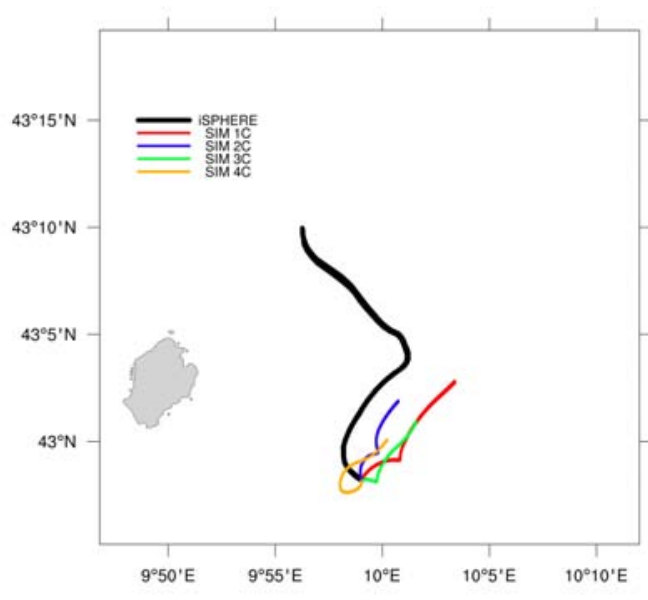

MAR-GE/T

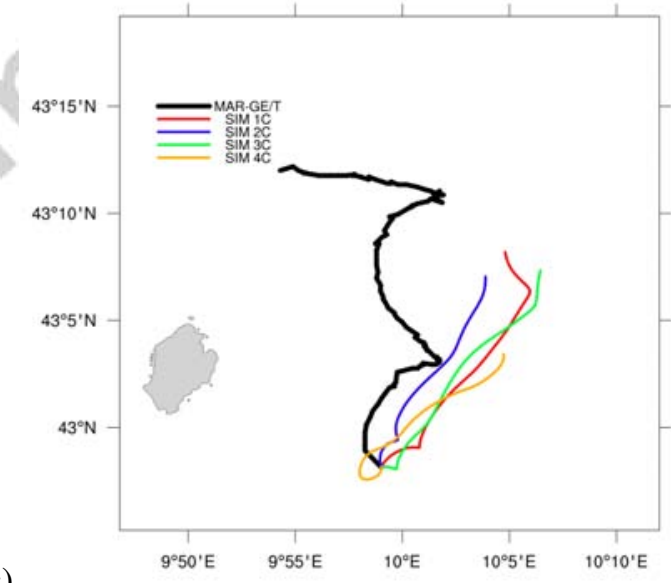

d)

Figure 7: MEDSLIK-II simulated trajectories forced by currents from ocean model listed in Tab. 5: a) CODE 24 hours trajectories; b) iSPHERE 24 hours trajectories; c) iSLDMB 48 hours trajectories; d) MAR-GE/T 48 hours trajectories. The drifter trajectories are the track of the barycentre of the particle cloud displacement, simulated with random walk procedure. 

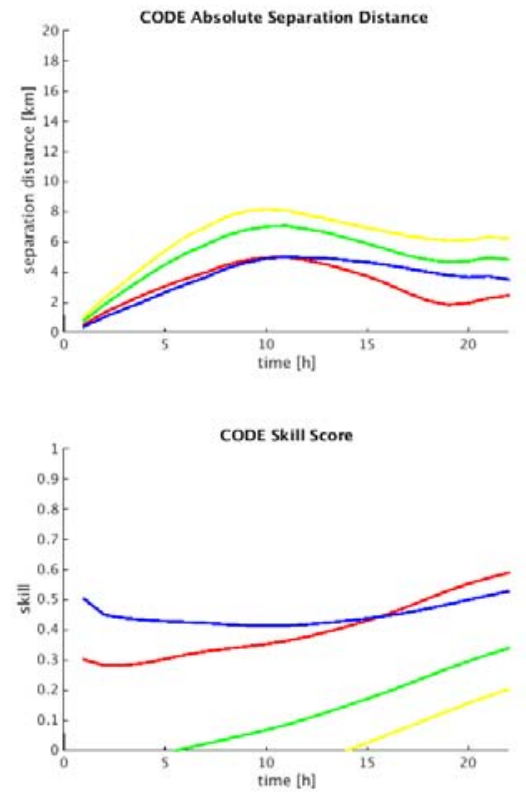
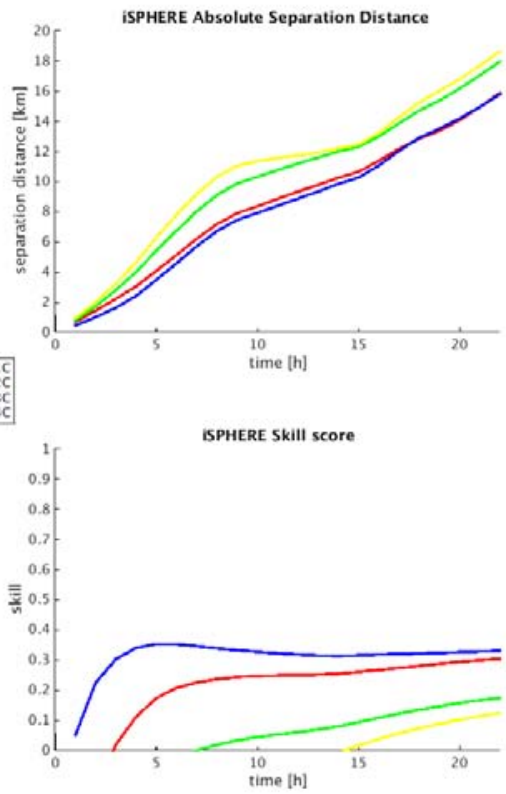

Figure 8: Absolute separation distances and skill scores as a function of the prediction time, for simulations listed in Tab. 5 for CODE and iSPHERE 24 hours trajectories. 

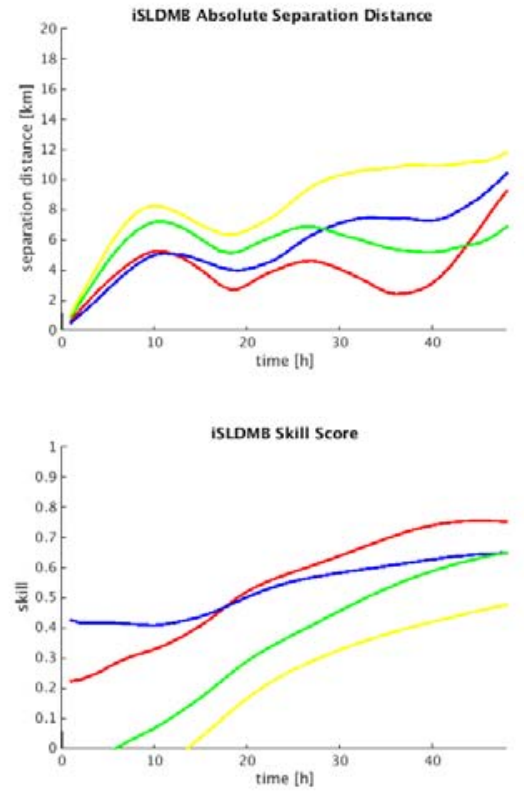
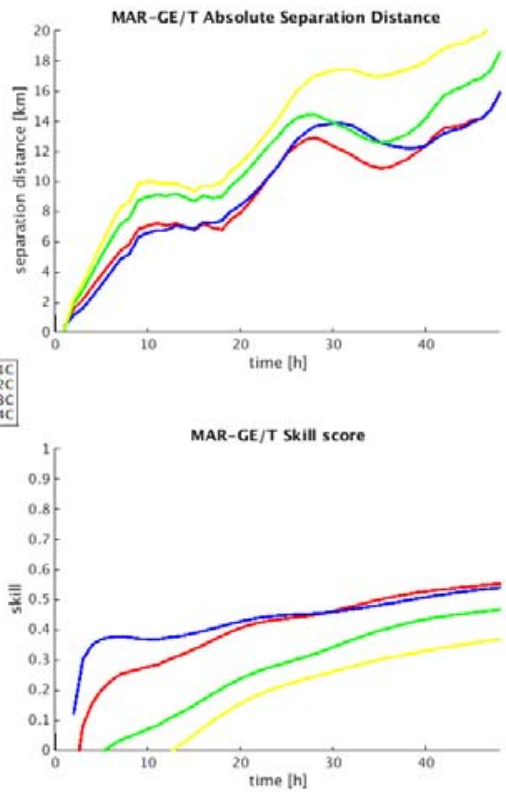

Figure 9: Absolute separation distances and skill scores as a function of the prediction time, for simulations listed in Tab. 5 for iSLDMB and MAR-GE/T 48 hours trajectories. 
CODE

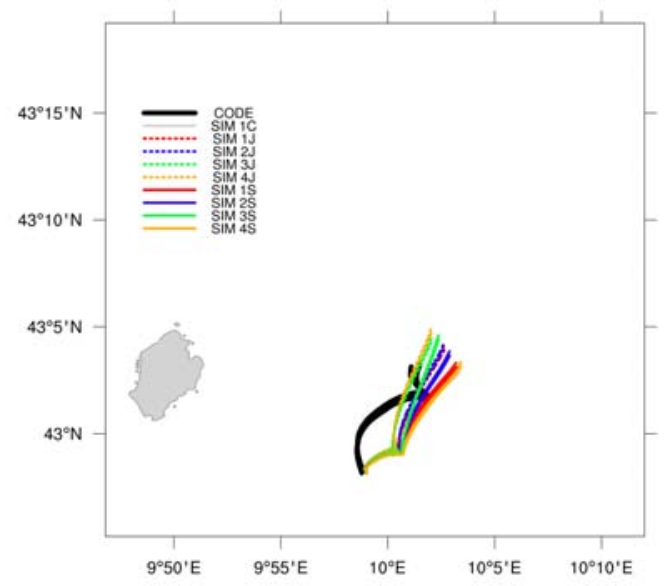

iSLDMB

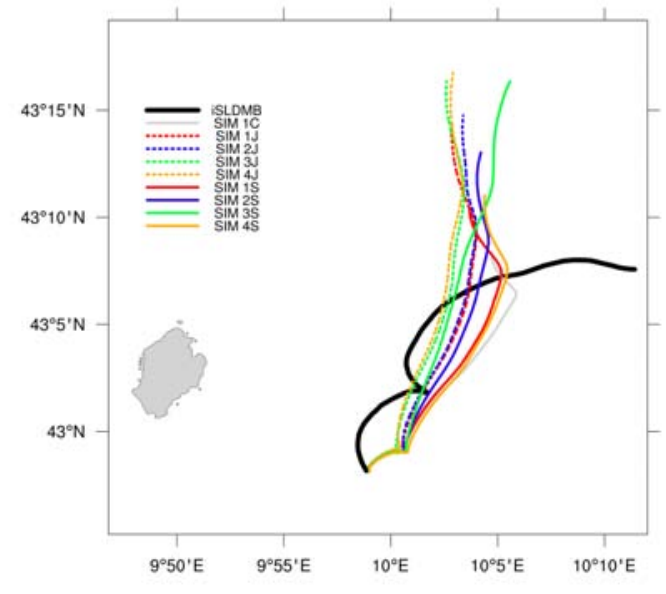

ISPHERE

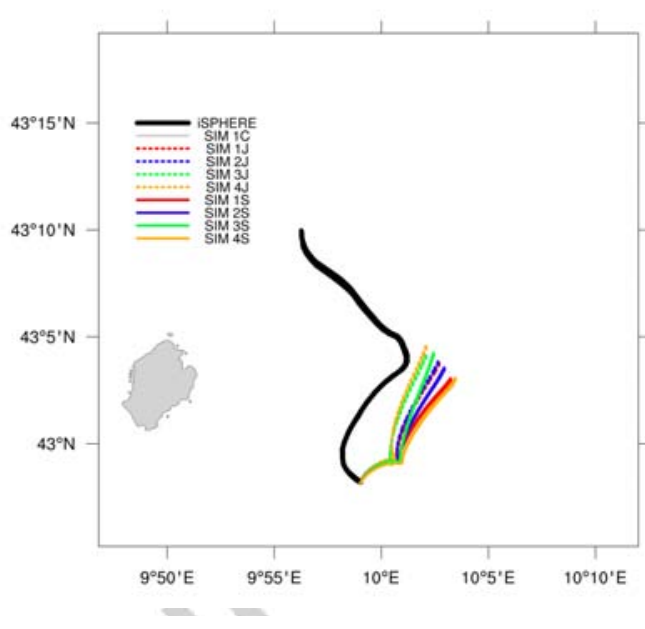

MAR-GE/T

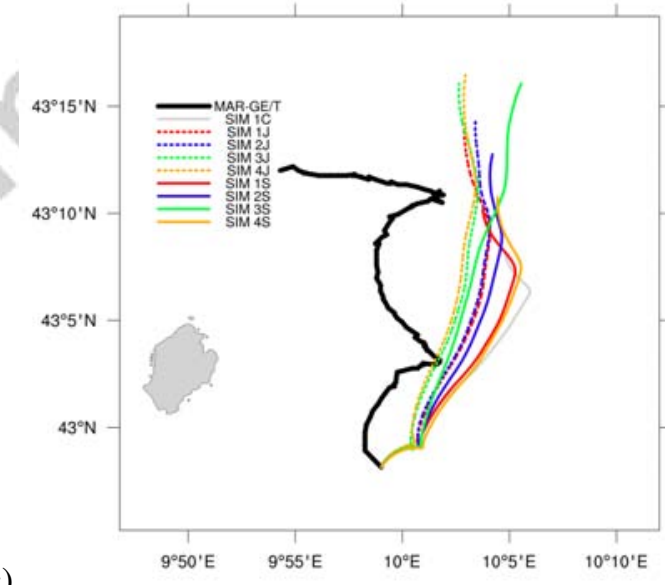

Figure 10: MEDSLIK-II simulated trajectories forced by currents with the addition of the Stokes drift provided by wave models or by JONSWAP parameterization, as listed in Tab. 6 and Tab. 7: a) CODE 24 hours trajectories; b) iSPHERE 24 hours trajectories; c) iSLDMB 48 hours trajectories; d) MAR-GE/T 48 hours trajectories. The drifter trajectories are the track of the barycentre of the particle cloud displacement, simulated with random walk procedure. 

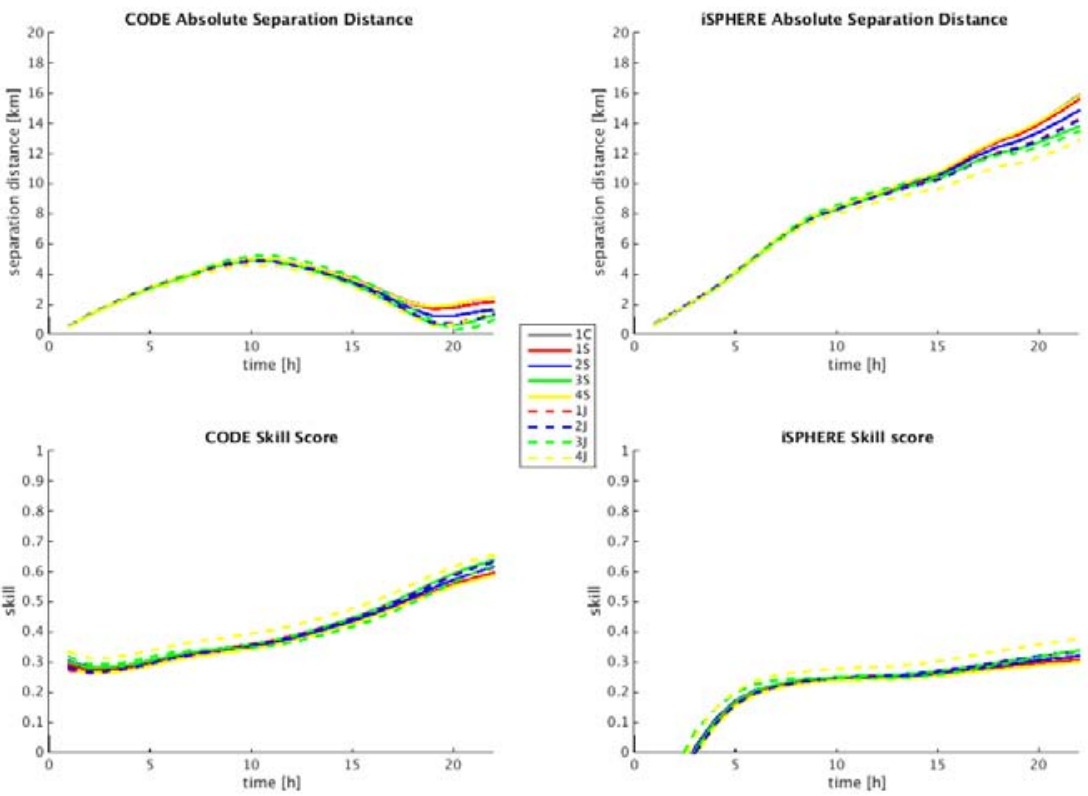

Figure 11: Absolute separation distances and skill scores as a function of the prediction time, for simulations listed in Tab. 6 and in Tab. 7 for CODE and iSPHERE 24 hours trajectories. 

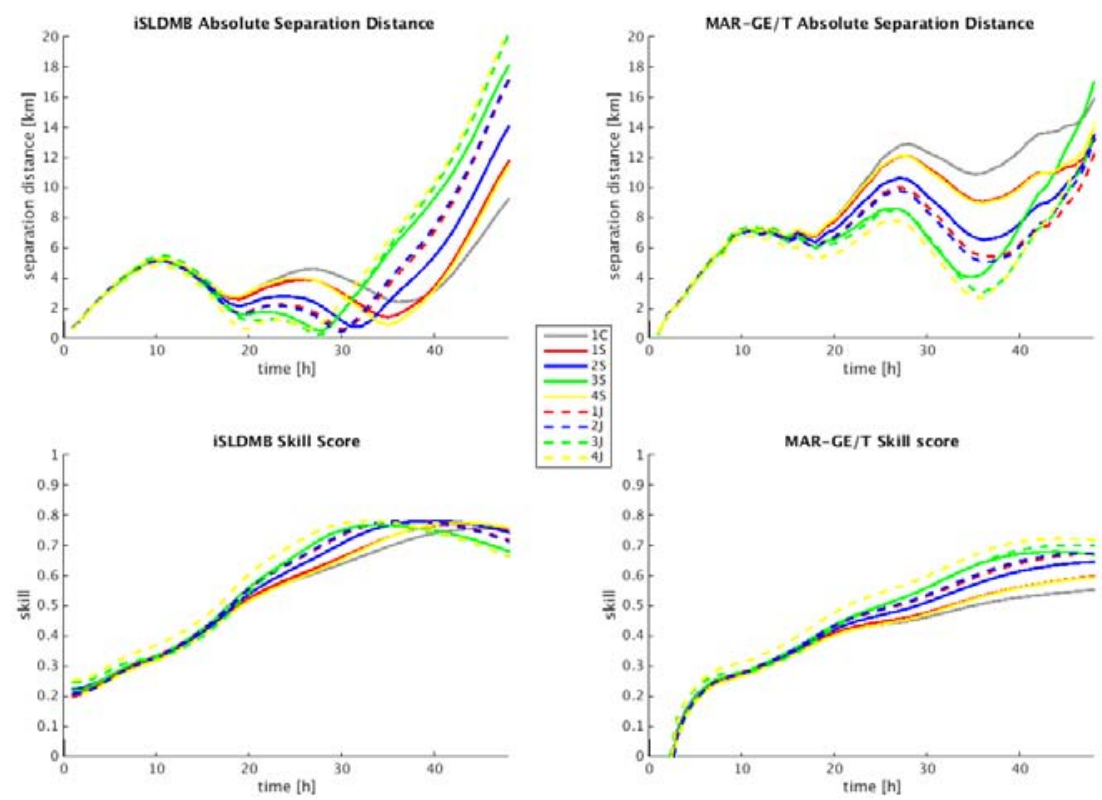

Figure 12: Absolute separation distances and skill scores as a function of the prediction time, for simulations listed in Tab. 5 for iSLDMB and MAR-GE/T 48 hours trajectories.

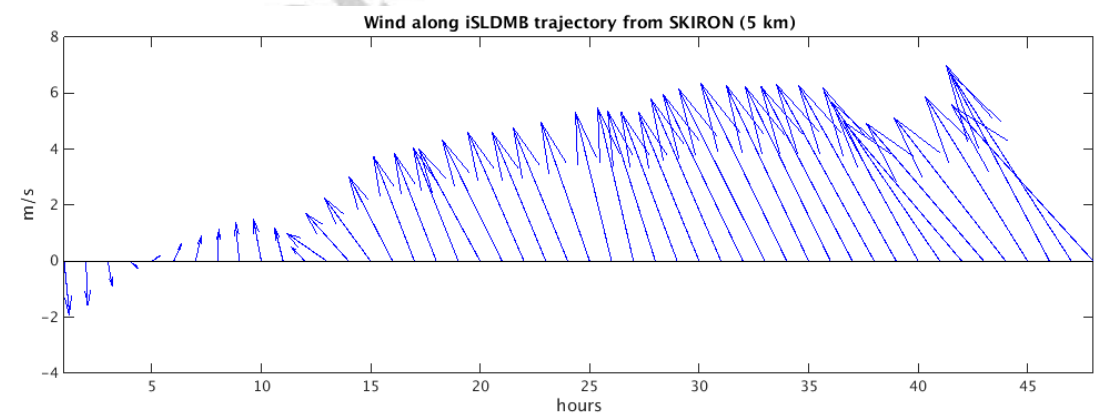

Figure 13: Wind along the iSLDMB drifter trajectory for 48 hours after the deployment (17 May 2014 at 12:00 UTC), from SKIRON wind model ( $5 \mathrm{~km}$ horizontal spatial resolution). The wind along CODE, SPHERE, MAR-GE/T shows the same pattern (not shown). 
CODE
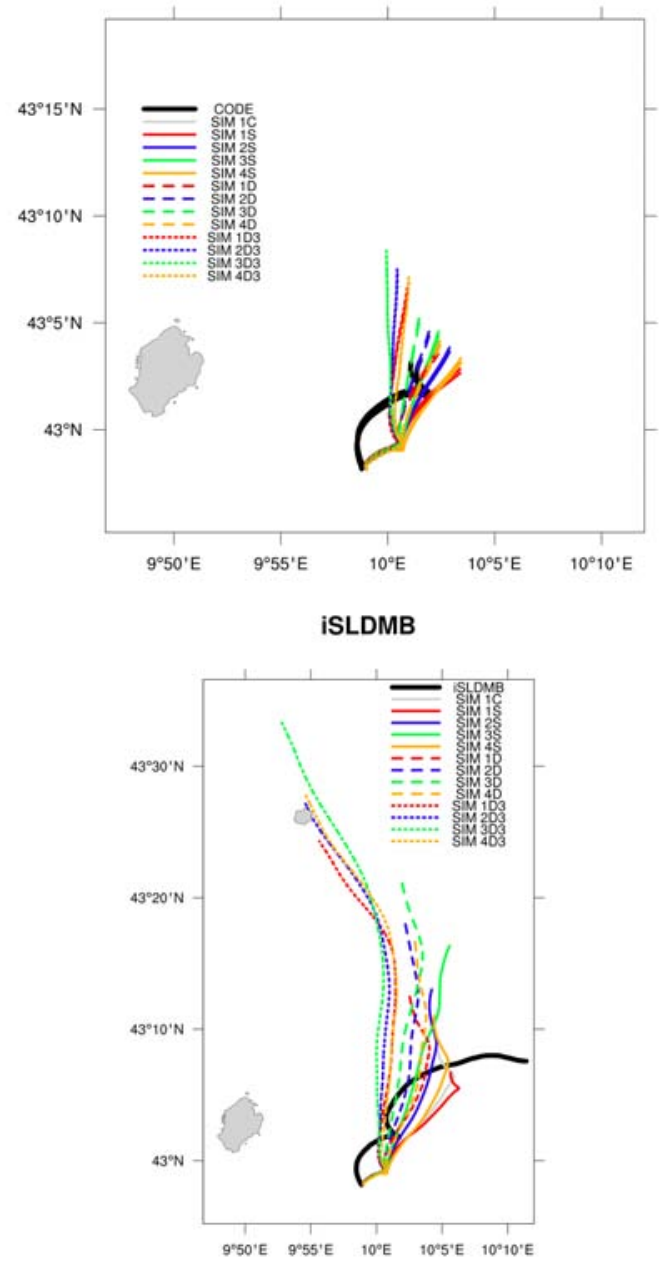

a)

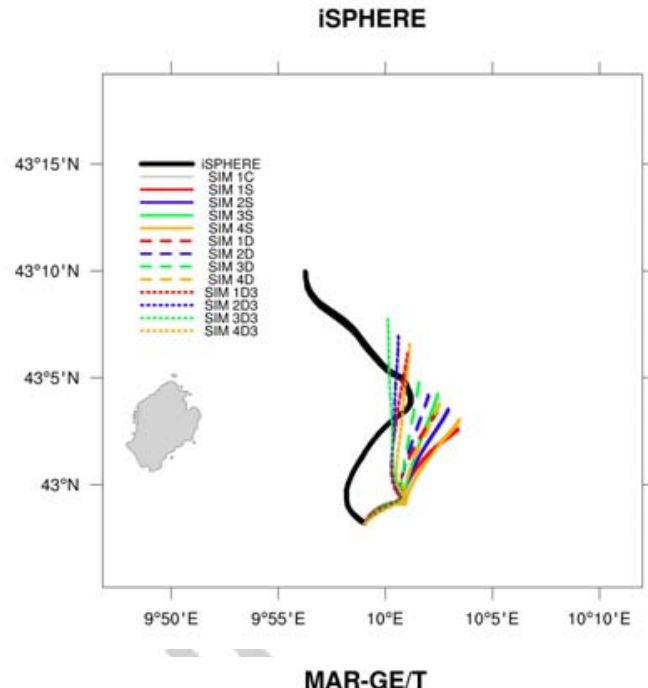

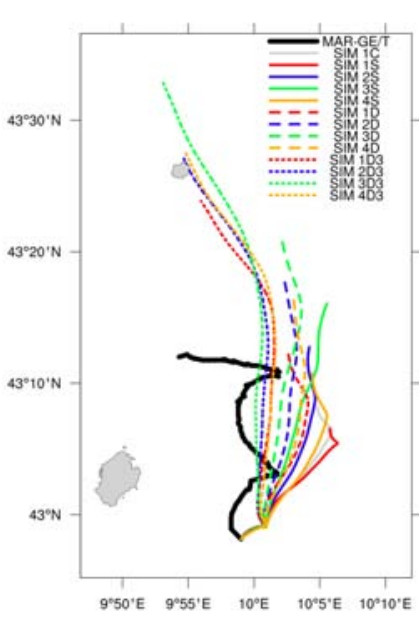

b)

c)

Figure 14: MEDSLIK-II simulated trajectories forced by currents, Stokes drift from wave models and wind drag velocity, as listed in Tab. 8: a) CODE 24 hours trajectories; b) iSPHERE 24 hours trajectories; c) iSLDMB 48 hours trajectories; d) MAR-GE/T 48 hours trajectories. The drifter trajectories are the track of the barycentre of the particle cloud displacement, simulated with random walk procedure. 

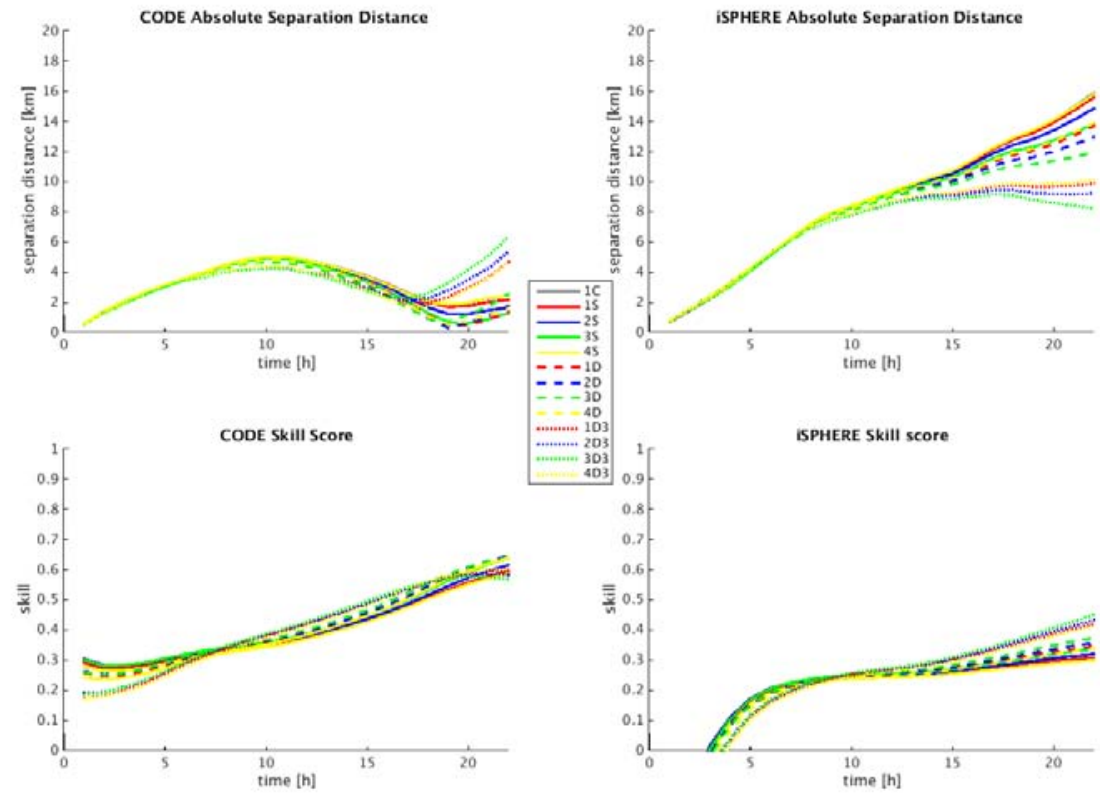

Figure 15: Absolute separation distances and skill scores as a function of the prediction time, for simulations listed in Tab. 8 for CODE and iSPHERE 24 hours trajectories. 

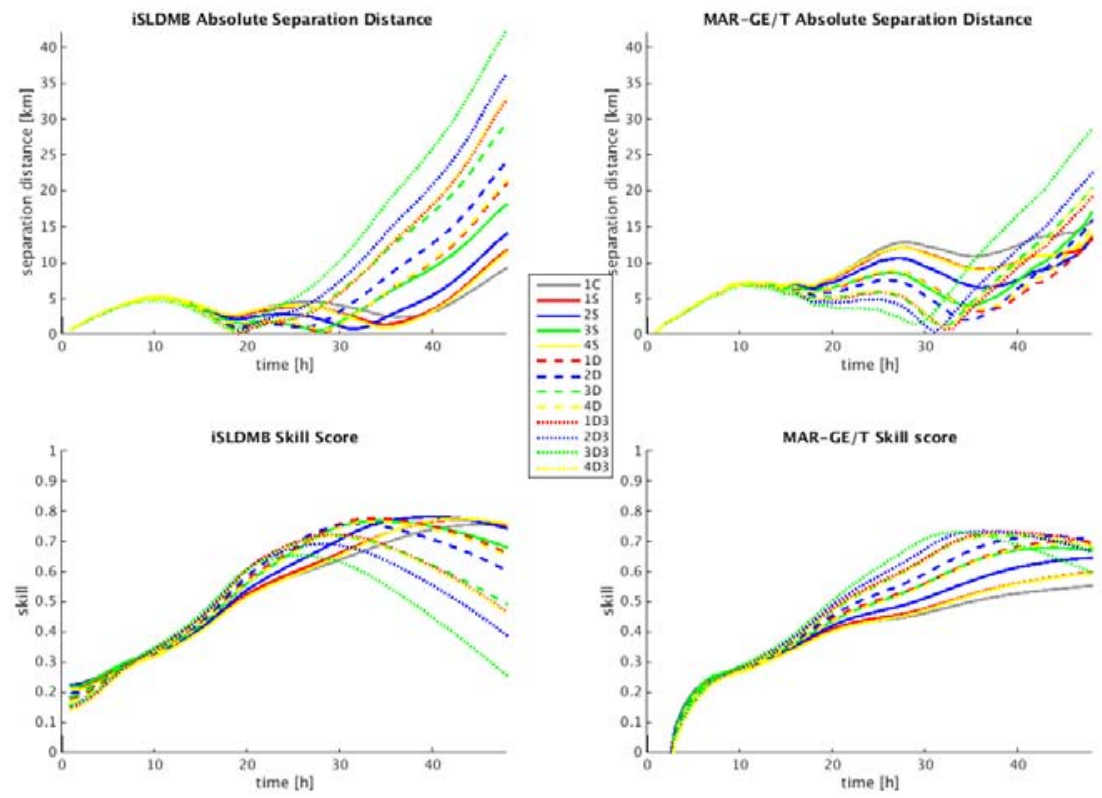

Figure 16: Absolute separation distances and skill scores as a function of the prediction time, for simulations listed in Tab. 8 for iSLDMB and MAR-GE/T 48 hours trajectories. 